\title{
ULTIMATE CAPACITY ASSESSMENT OF WEB PLATE BEAMS WITH PITTING CORROSION SUBJECTED TO PATCH LOADING BY ARTIFICIAL NEURAL NETWORKS
}

\author{
Yasser Sharifi* and Sajjad Tohidi \\ Department of Civil Engineering \\ Vali-e-Asr University of Rafsanjan, Rafsanjan, Iran \\ *(Corresponding author: E-mail: yasser_sharifi@yahoo.comory.sharifi@vru.ac.ir or)
}

Received: 17 May 2013; Revised: 19 October 2013; Accepted: 22 October 2013

\begin{abstract}
Corrosion is an unavoidable phenomenon in ship hull structures and thickness loss of the structural members due to corrosion is a great concern when the integrity of hull structures is considered. It is well known that pitting corrosion occurring on coated hold frames will surely result in a significant degradation of the ultimate strength of these members. Extensive study on the effect of pitting corrosion on structural strength under a wide variety of loading conditions is necessary to assess the relationship between pitting corrosion intensity and residual strength precisely. The aim of the present study is to investigate the ultimate strength characteristics of steel beams with pit and uniform corrosions wastage. Then pitted member will predict with a member that its thickness decreases uniformly in terms of ultimate strength. A series of ABAQUS nonlinear elastic-plastic analyses by Finite Element Method (FEM) has been carried out on I-shape section steel models, varying the degree of pit corrosion intensity. Load-carrying capacity of deteriorated steel beam models with different pit corrosion under patch loading has been estimated using Artificial Neural Network (ANN) method using FE results. The ultimate strength reduction factor due to web pitting corrosion of steel beams is empirically derived by ANNs of the computed results as a function of DOP. Hence, the results of this study can be used for better prediction of the failure of deteriorated steel beams by practice engineers.
\end{abstract}

Keywords: Pitting corrosion, steel structures, nonlinear FE analyses, patch loading, artificial neural networks

\section{INTRODUCTION}

Steel structures such as ships, offshore platforms, and land-based structures are prone to suffer various types of damage while service. Carbon steel is one of the most widely used materials in these structures. A typical characteristic of deterioration of carbon steel structures exposed to aggressive chloride environments is corrosion. Corrosion can affect the structural performance in several ways. Corrosion wastage in steel beams can reduce their ultimate strength. It is of vital importance to estimate the residual strength of damaged structures for many reasons. For instance, it is essential to seek rational standards for the structural integrity of aging structures without economic penalties with respect to the repair and maintenance schemes are normally applied for that purpose. Within the scheme of ultimate limit state based risk or reliability assessment for aging structures, closed-form expressions for predicting the ultimate strength of structural members taking account of the effect of structural damage are required. In addition improperly maintained ageing ship structure could finally lead to disastrous casualties in rough seas and heavy weather. Thus, it is important to assess the residual strength of ageing ship structure properly either with corrosion or with other type of defects in order to reflect vessel's inspection and maintenance programme (Nakai et al. [1-3]; Paik et al. [4-5]; 2006; Sharifi and Paik [6-7]; Sharifi [8]; Sharifi and Tohidi [9]). Despite a large number of procedures to keep steel structures from corrosion attack such as painting and galvanizing, there are numerous existing structures which have not preserved so far. Beside this, in several points these preservations such as painting break down and the corrosive environment attack to the pure steel and make it damaged. Therefore, assessment the residual strength of these structures is an important issue to keep them in a reliable and safe utilization. Totally, corrosion divided into two principal types, that is, general and localized 
corrosions in the land-based structures, marine, offshore and industry structures. Pitting corrosion which is considered in this study is categorized as a form of localized corrosion (Nakai et al. [1-3]). For general corrosion, which uniformly reduces plate thickness, the plate ultimate strength calculations are typically carried out excluding the thickness loss due to corrosion. For localized corrosion such as pitting or grooving, the strength calculation procedure can be more complex, and for a simplified pessimistic treatment, the corroded plates have been idealized using an equivalent general corrosion. However, this treatment is not always relevant since it is not straightforward to define the equivalent general corrosion properly. Therefore, In the case of the members with pitting corrosion the evaluation of residual strength is considered to be more difficult compared to members with uniform corrosion (Nakai et al. [1-3]; Paik et al. [4-5]; 2006; Sharifi and Paik [6-7]; Sharifi [8]). When beam strength is considered, in general, collapse strength (no buckling), lateral-distortional buckling strength, local buckling strength, shear strength of web plates and web crippling strength under concentrated loading are important factors (Nethercot [10]). Therefore, it is obvious that there is a need for further research to investigate the effect of pitting corrosion on each mentioned factor. Patch load action on steel girders are frequently encountered in marine structures and civil engineering practice. This type of loading can be found in ship or crane girders, secondary beams reaction acting over the primary girder system and other structural problem. In addition for bridge girders, the major problem concerning the load carrying capacity due to concentrated forces occurs during launching. During this operation, the launching rollers or plates introduce concentrated forces through the bottom flange into the girder web, a load case usually called patch loading. FEA method has now become the most common, powerful and flexible tool in rational structural analysis and makes it possible to predict the strength of complex structures more accurately than existing classical theoretical methods. Over last decades there has been significant development of computer hardware and FEA software. Although finite-element method can be used, in principle, to predict buckling and post buckling strengths, it still requires quite much computational time and cost. For this reason and above-mentioned reasons some useful empirical formulae to assess structural integrity during the initial design, inspection and maintenance are always necessary for effective and on-site decisions. ANN method recently have been introduced in structural engineering problems. ANN represents a useful of the biologic neural structures of 326the central nervous system. Attempts to use ANN in structural engineering problems are introduced by several researchers (Adeli and Hung [11]; Fonseca et al. [12]; Jang [13]; Hagan and Menhaj [14]; Guzelbey et al. [15]).

In this paper, a series of ABAQUS nonlinear elastic-plastic analyses by FEM has been carried out on I-shape section steel models, varying the degree of pit corrosion intensity. In these models, artificial pitting with different intensities was made on the web plates and two equal concentrated loads have been applied vertically at the one third points of the simply supported models as shown in Figure 1. Meanwhile, load-carrying capacity of deteriorated models with different uniform thickness loss on the web has been also developed. Then, the ANN method has been employed to derive new empirical formulae for load carrying capacity of damaged models in terms of DOP. Based on the results, the ultimate strength of the web plates with different pitting corrosion intensities has been predicted with a uniform loss thickness; therefore, formulae for estimating the average loss thickness and hence load-carrying capacity have been also developed here.

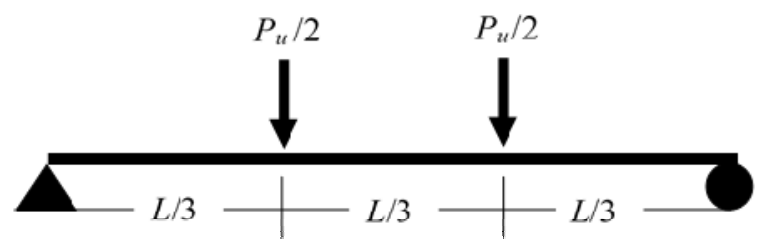




\section{2.}

Figure 1. Loading Condition

Figure 2 shows some of the more important types of corrosion related damages which affect the strength of steel structures. 'General' corrosion (also called 'uniform' corrosion) uniformly reduces the thickness of structural members as shown in Figure 2(a), while localized corrosion (e.g., pitting or grooving) causes degradation in local regions as shown in Figure 2(b). Sometimes fatigue cracks may arise from localized corrosion, as shown in Figure 2(c). The corrosion damage of steel structures is influenced by many factors, including the corrosion protection system and various operational parameters. In general, the corrosion protection systems employed for ships or offshore platforms are coatings (paint) and anodes. The operational parameters include maintenance, repair, percentage of time in ballast, frequency of tank cleaning, temperature profiles, use of heating coils, humidity conditions, water and sludge accumulation, microbial contamination, composition of inert gas and so on. To date, basic work to understand the effects of many of these factors and their interactions is lacking in the case of marine structures (Paik et al. [4-5]; 2006; Sharifi and Paik [6-7]; Sharifi [8]).

(a)

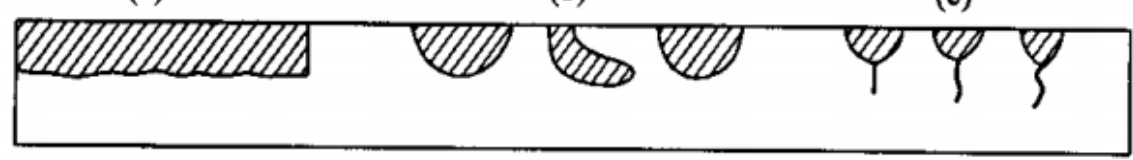

Figure 2. Typical Modes of Corrosion Damage: (A) General (Uniform) Corrosion;

(B) Localized Corrosion; (C) Fatigue Cracks Arising from Localized Corrosion

Pitting corrosion as the principal factor for deteriorated structures in corrosive environments has been used here. To assess the scale of breakdown due to pit corrosion, a parameter denoted DOP (degree of pit corrosion intensity) is often used, where DOP is defined as the ratio percentage of the corroded volume to the original plate volume, namely,

$D O P=\sum_{i=1}^{n} \frac{V_{p i}}{a b t} \times 100(\%)$

where $n$ is the number of pits, $V_{p i}$ is the volume of the $i t h$ pit, $a$ is the plate length, $b$ is the plate breadth and $t$ is the plate thickness.

Figure 3 shows pit shape and typical sample of pit corrosion damage distribution in web plates. Although the distribution of the pit corrosion on the plates is scattered, it can be seen that the shape of the corrosion is typically cylindrical. Our investigation of the web girder plate assumes that both sides of it will corrode in a localized manner. It is also assumed that pitting corrosion, which is uniformly distributed, affects the strength of the following plates by the different degrees of intensity shown in Figure 3. Finally, it is assumed that the pit diameter to the depth is 8, and the distance between the adjacent pits centers is constant. 


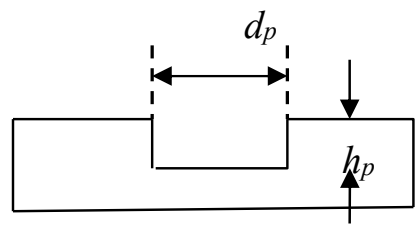

a)

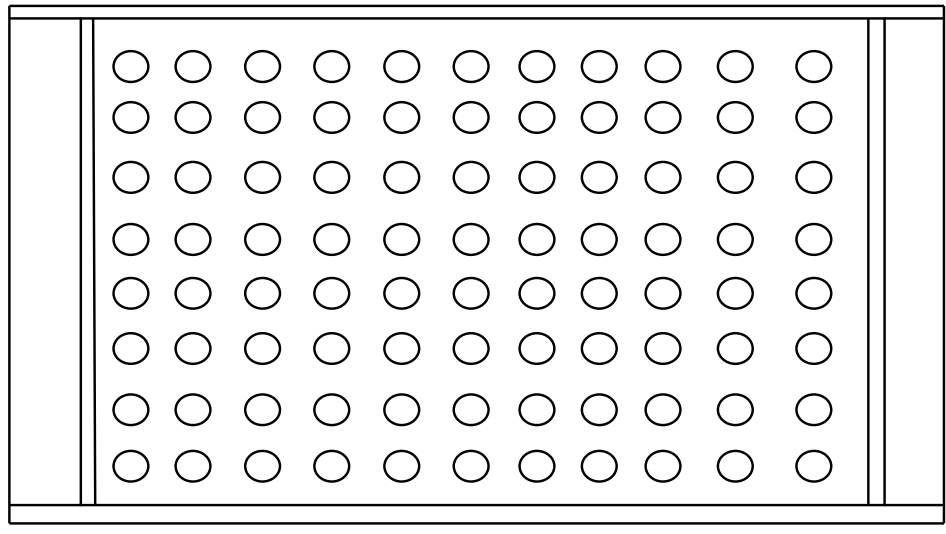

b)

Figure 3. Pit Shape (A), and Pit Distribution (B) on the Beam Web

\section{PATCH LOADING REVIEW}

Patch loading is a significant phenomenon for steel beam and girders. Steel beams or girders are often subjected to concentrated loads commonly named as patch loading which directly determines the proportioning of the section. The failure mode of unstiffened webs subjected to patch loading is very local, and a buckle appears under the compression flange. To a large extent the size of the buckle depends on the dimensions of the loaded flange. Patch load action on steel girders are frequently encountered in marine structures and civil engineering practice. This type of loading can be found in bridge, ship and crane girders, secondary beams reaction acting over the primary girder system and other structural problem. For bridge girders, the major problem concerning the load carrying capacity due to concentrated forces occurs during launching. During this operation, the launching rollers or plates introduce concentrated forces through the bottom flange into the girder web, a load case usually called patch loading. The collapse strength of an unstiffened web subjected to patch (transverse) loads applied through a plate girder flange is governed by one of the following three failure mode (EN 1993-1-1 [16]):

1- crushing of the web close to the flange, accompanied by plastic deformation of the flange;

2- crippling of the web in the form of localized buckling and crushing of the web close to the flange, accompanied by plastic deformation of the flange; and

3- buckling of the web over most of the depth of the plate girder.

Two types of load application are normally considered: (1) forces applied through one flange and resisted by shear forces in the web; or (2) forces applied to one flange and transferred through the web directly to the other flange. For load type (1), the capacity of the web to lateral forces may be determined as the smaller value of the two strengths due to crushing and crippling. For load type (2), the web capacity may be taken as the smaller value of the two strengths due to crushing and buckling. The crippling strength of a web with intermediate transverse stiffeners is similar to that of an 
unstiffened web, with the increase due to stiffeners (Paik and Thayamballi, [17]). Dogaki et al. [18] studied the ultimate strength of longitudinally stiffened plate girders under patch loading. They concluded that the optimum location of the longitudinal stiffener close to the plate girder flange under patch loading is about $b_{w}=0.15 h_{w}$. Dogaki et al. [19] then proposed an empirical expression of the ultimate strength, $P_{u}$, of plate girder under patch loading by curve fitting based on their own test results, as follows:

$$
\frac{P_{u}}{2 V_{P}}=\frac{0.594}{\lambda}+0.069
$$

For plate girder without longitudinal stiffeners under patch loading, Takimoto [20] proposed a closed-form expression of the ultimate strength, $P_{u}$, as follows:

$$
P_{u}=\left(25 t_{w}^{2} \sigma_{Y w}+4 t_{w} t_{f} \sigma_{Y f}\right)\left(1+\frac{S_{s}+2 t_{f}}{2 h_{w}}\right)
$$

where the plastic shear strength is $V_{P}=h_{w} t_{w} \tau_{Y}, \tau_{Y}=\frac{\sigma_{Y w}}{\sqrt{3}}$ is the shear yield strength, $\sigma_{Y w}$ is the web yield strength, $h_{w}$ is the high of the web plate, $t_{w}$ is the web thickness, $\lambda=\sqrt{\frac{2 V_{P}}{P_{E}}}$ is buckling parameter, and $P_{E}$ is elastic buckling strength of plate girder web under patch loading, taking into account the effects of flexural and torsional rigidities of the flange (Paik and Thayamballi, [17]). Roberts and Rockey [21] investigated the collapse loads of slender plate girders when subjected to in-plane patch loading. They proposed a solution for the ultimate capacity of unstiffened plate girders with slender webs subjected to concentrated loading based on a yield line mechanism composed of four plastic hinges in the flange and three yield lines in the web. Bergfelt [22] has treated the problem of patch loading on a slender web-influence of horizontal and vertical web stiffeners on the load carrying capacity. He proposed a formula for predicting the ultimate resistance of plate girders under patch loading.

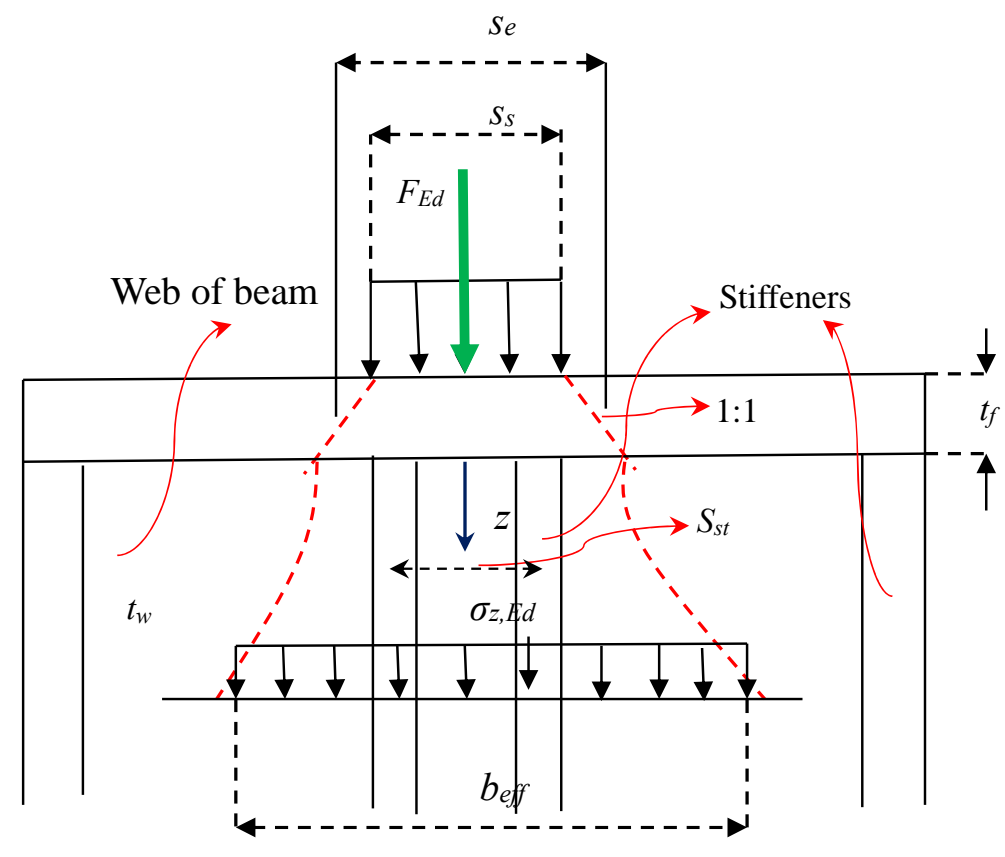

Figure 4. In-Plane Load Introduction 
For a stiffened or unstiffened girder web with infinite depth the maximum elastic stress due to the local introduction of in-plane forces (patch loads) at a distance $z$ below the patch load is shown in Figure 4. The elastic stress ( $\left.\sigma_{z, E d}\right)$ was given by (EN 1993-1-5, [23]):

$$
\sigma_{z, E d}=\frac{F_{E d}}{b_{e f f}\left(t_{w}+a_{s t, l}\right)}
$$

where

$$
\begin{aligned}
& b_{\text {eff }}=s_{e} \sqrt{1+\left(\frac{z}{s_{e} n}\right)^{2}}, \\
& n=0.636 \sqrt{1+\frac{0.878 a_{s t, l}}{t_{w}}}, \\
& s_{e}=s_{s}+2 t_{f} .
\end{aligned}
$$

where,

$a_{s t, l}$ is the gross cross-sectional area of the stiffeners smeared over the length $s e$. This may be taken, conservatively, as the area of the stiffeners divided by the spacing $s_{s t} ; t_{w}$ is the web thickness; $t_{f}$ is the flange thickness; $z$ is the distance to flange; and $s_{s}$ is the length of patch load can be seen in Figure 4. It should be noted that the equation (4) is valid when $\frac{s_{s t}}{s_{e}} \leq 0.5$, otherwise the contribution of stiffeners should be neglected.

Lagerqvist and Johansson [24] investigated the resistance of I-girders to concentrated loads. They presented the design model for the patch loading resistance of unstiffened plate girders. Those model was based on the post-critical strength of the plate girders by the use of stability checks using buckling curves for the patch loading resistance. This model was the basis for the formula in EN 1993-1-5 [23] in which the patch loading resistance for unstiffened plate girders $F_{R d}$ is given by:

$F_{R d}=\frac{f_{y w} L_{e f f} t_{w}}{\gamma_{M l}}$

where $f_{y w}$ is the yield strength of the web;

EN 1993-1-1 [16] recommends a value $\gamma_{M I}=1.0$ and in these equations, $L_{\text {eff }}$ is the effective length for resistance to transverse forces given by:

$$
L_{\text {eff }}=\chi_{F} l_{y}
$$

where $l_{y}$ is the effective loaded length appropriate to the length of stiff bearing $s_{s}, \chi_{F}$ is the reduction factor due to local buckling and can be obtained as following:

$\chi_{F}=\frac{0.5}{\bar{\lambda}_{F}} \leq 1.0$ 
where $\bar{\lambda}_{F}=\sqrt{\frac{l_{y} t_{w} f_{y w}}{F_{c r}}}$,

in which the effective loaded length given by:

$l_{y}=\left\{\begin{array}{l}s_{s}+2 t_{f}\left(1+\sqrt{m_{1}+m_{2}}\right) \leq \text { distance between adjacent transverse stiffeners } \\ \min \left\{l_{e}+t_{f} \sqrt{\frac{m_{1}}{2}\left(\frac{l_{e}}{t_{f}}\right)^{2}+m_{2}}, l_{e}+t_{f} \sqrt{m_{1}+m_{2}}\right\}\end{array}\right.$

where $t_{f}$ is thickness of flange and the dimensionless parameters $l_{e}, m_{l}$ and $m_{2}$ are

$l_{e}=\frac{k_{F} E t_{w}^{2}}{2 f_{y w} h_{w}} \leq s_{s}+c$

$m_{1}=\frac{f_{y f} b_{f}}{f_{y w} t_{f}}$

$m_{2}=\left\{\begin{array}{lll}0.02\left(\frac{h_{w}}{t_{f}}\right)^{2} & \text { if } & \bar{\lambda}_{F}>0.5 \\ 0 & \text { if } & \bar{\lambda}_{F} \leq 0.5\end{array}\right.$

where $f_{y f}, b_{f}$ and $t_{f}$ are yield stress, width and thickness of flange beam, $E$ is the modulus of elasticity of beam steel, and $h_{w}$ is depth of web panel. It should be noted that $m_{2}$ should be taken as zero for welded girders if $\bar{\lambda}_{F}<0.5$ in which $\bar{\lambda}_{F}$ is the slenderness parameter.

$F_{c r}$ is the buckling load which is expressed as:

$F_{c r}=0.9 k_{F} E \frac{t_{w}^{2}}{h_{w}}$

As shown in Figure 5 the buckling coefficient $k_{F}$ is given by:

$k_{F}= \begin{cases}6+2\left(\frac{h_{w}}{a}\right)^{2} & \text { For type (a) } \\ 3.5+2\left(\frac{h_{w}}{a}\right)^{2} & \text { For type (b) } \\ 2+6\left(\frac{s_{s}+c}{h_{w}}\right) \leq 6 & \text { For type (c) }\end{cases}$

Where $a$ and $c$ have been shown in Figure 5 . 
Type (a)

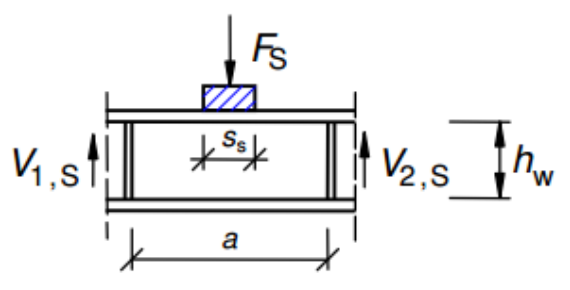

Type (b)

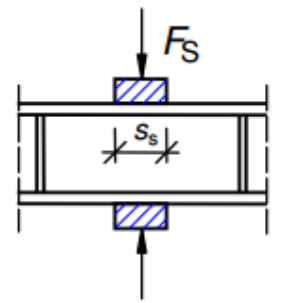

Type (c)

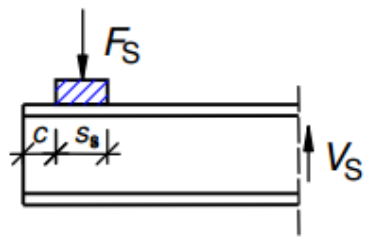

Figure 5. Buckling Coefficients for Different Types of Load Application

\section{FINITE ELEMENT MODEL SIMULATION}

As mentioned, in the present study it has been decided to demonstrate the ultimate strength reduction characteristics of a beam web plate with pit corrosion and under patch loading by ABAQUS nonlinear FE analysis [25]. The strength of pitted web plates is determined by nonlinear finite element analysis, changing geometrical features of pits, which allows for identification of the effect of the pitting corrosion on ultimate strength of web plate beams. An elasto-plastic analysis has been conducted to simulate the effect of corrosion pit on ultimate strength behavior. Moreover, in order to verification of simulation an experimental or correct FE results is needed. Therefore, it was decided to compare current FE results with Nakai et al. [1] experimental work which consider a model shown in Figure 6a. As it can be seen from Figure 7b our modeling and boundary conditions match with this model.

For initial geometric imperfection of the models, the average level of maximum deflection is approximately taken as $W o / 10$ according to the measured data (Nakai et al. [1]). The deformation is consistent with the buckling mode by eigenvalue analysis. Based on previous studies such as one by Nakai et al [1], effect of welding residual stress is not remarkable and has no effect on the results in case of assessment of ultimate strength of web plate. Moreover, a primary concern in the present analysis is the ultimate strength reduction characteristics due to pit corrosion, i.e., the ultimate strength ratio of the corroded web plate beam to the perfect (un-corroded) (control specimen) ones. Therefore, in the present study the effect of welding residual stress has been neglected.

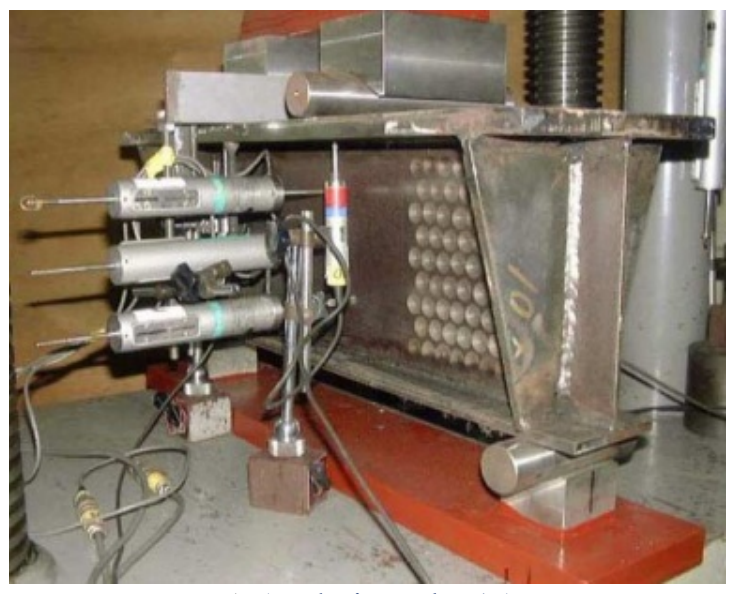

a) (Nakai et al. [1]) 


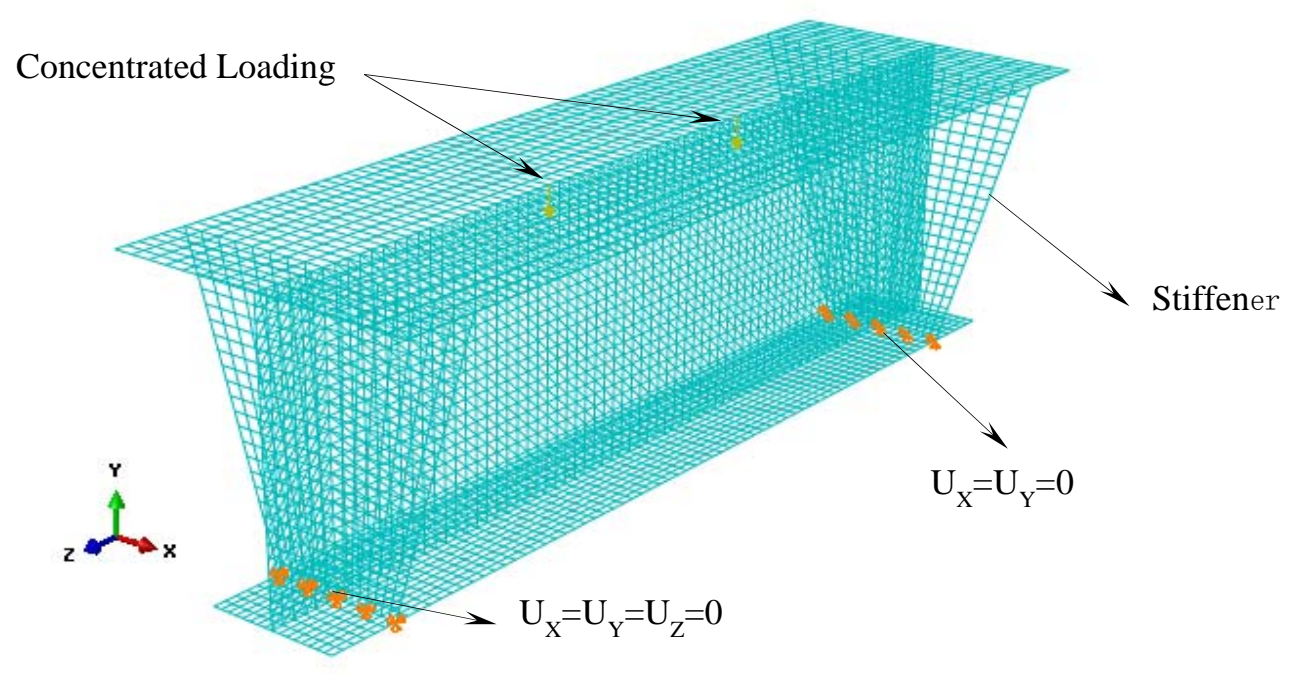

b)

Figure 6. Model and Boundary Condition of Beam Web Plate

\section{VALIDATION OF THE MODELING TECHNIQUE}

To validate the finite element analysis, a simply supported beam under patch loading (A4-1) which is similar to the model of Nakai et al. [1] was analyzed. The material of web plates and flanges in steel beam structures are given in Table 1 . Thickness of the plates is 6, 10 and $19 \mathrm{~mm}$. The Young modulus and Poisson ratio are $E=205800 \mathrm{MPa}$ and $v=0.3$, respectively. The geometrical model and load direction used in the FE analysis is as same of Reference [1]. The load-vertical deflection and load-lateral deflection from Nakai et al [1] and the current results are shown in Figurs 7, where the curves in both cases present a consistent tendency and the ultimate strength of beams match excellently. The maximum load obtained by FEA was $773.8 \mathrm{kN}$, which is about $5 \%$ lower than the experimental test specimen (778 $\mathrm{kN}$ ). This comparison has the objective of validating the present results with other published results so as to provide confidence that the FEM simulation in the current work can predict accurately the decreased ultimate strength of beams subjected to pitting corrosion.

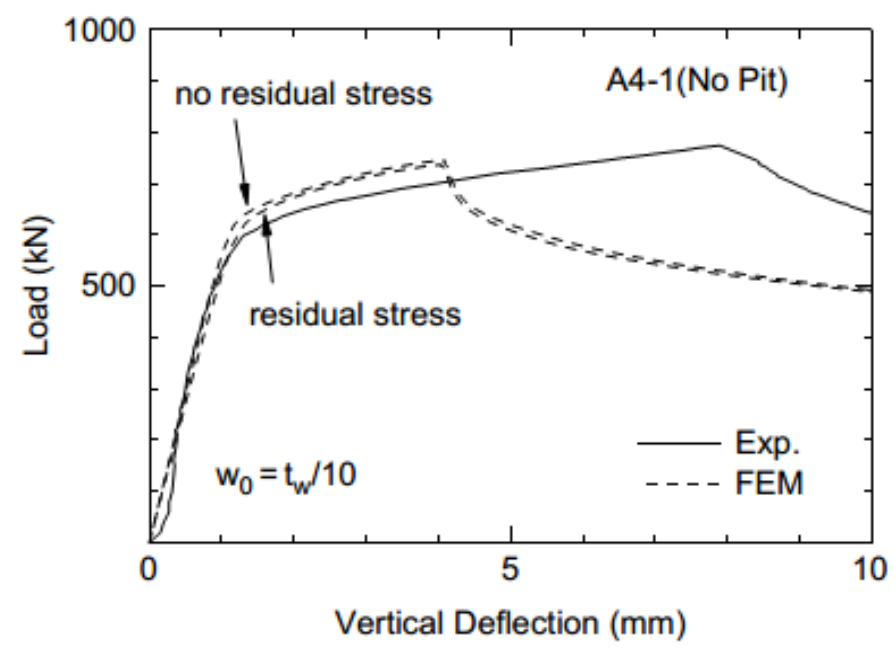




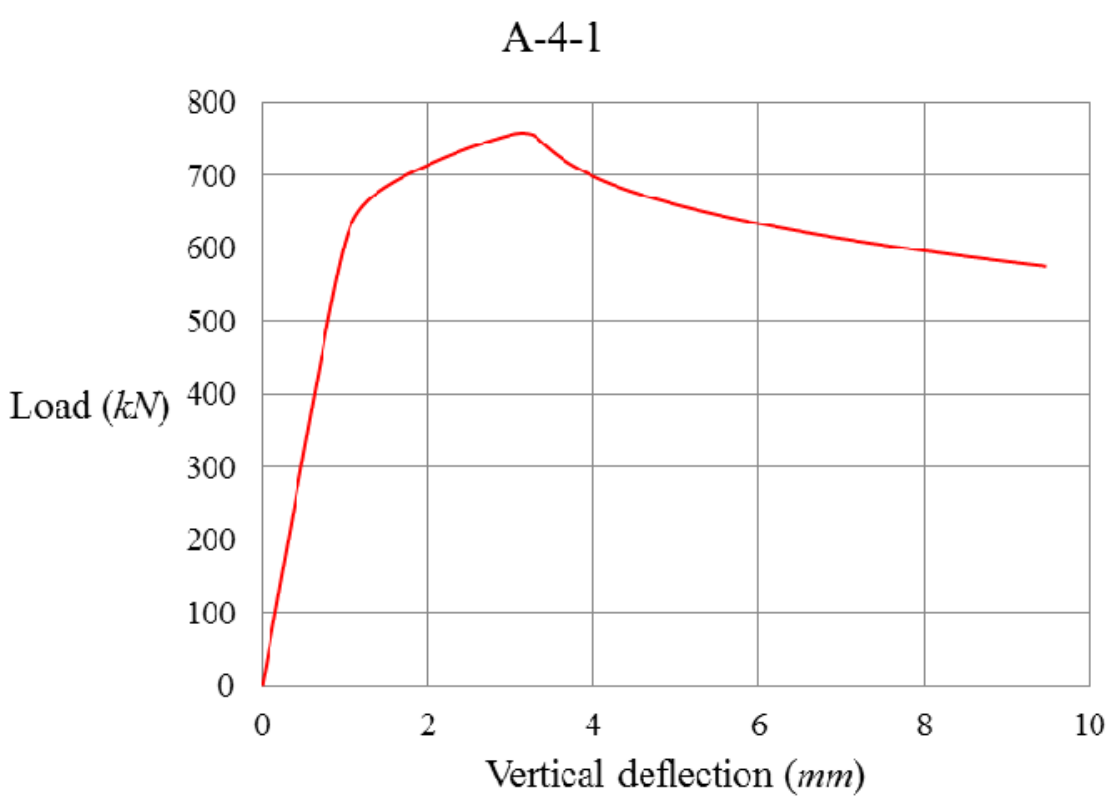

Figure 7a. Load - Vertical Deflection Curves under Patch Loading of Beams (Top from Ref. [1], bottom is result of present work)

Table 1. Mechanical Properties of Tested YP32 Steel

\begin{tabular}{cccc}
\hline$t(\mathrm{~mm})$ & $Y . P(\mathrm{MPa})$ & $T . S(\mathrm{MPa})$ & EI. $(\%)$ \\
\hline 6 & 421 & 544 & 30 \\
\hline 10 & 352 & 516 & 33 \\
\hline 19 & 331 & 508 & 33 \\
\hline
\end{tabular}

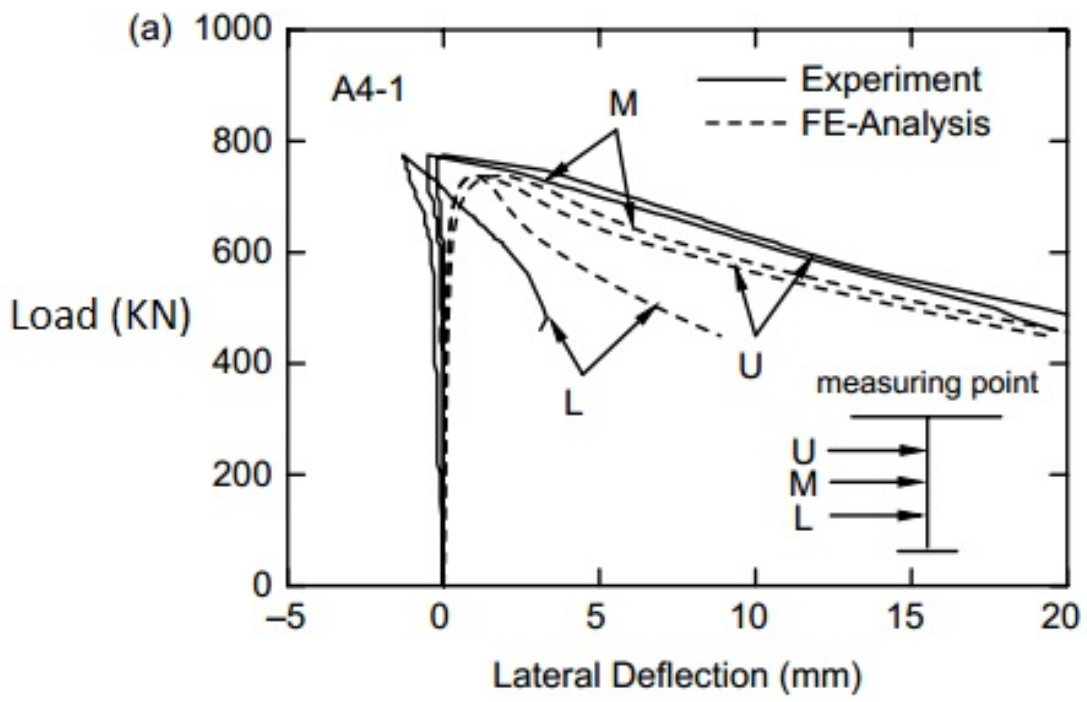




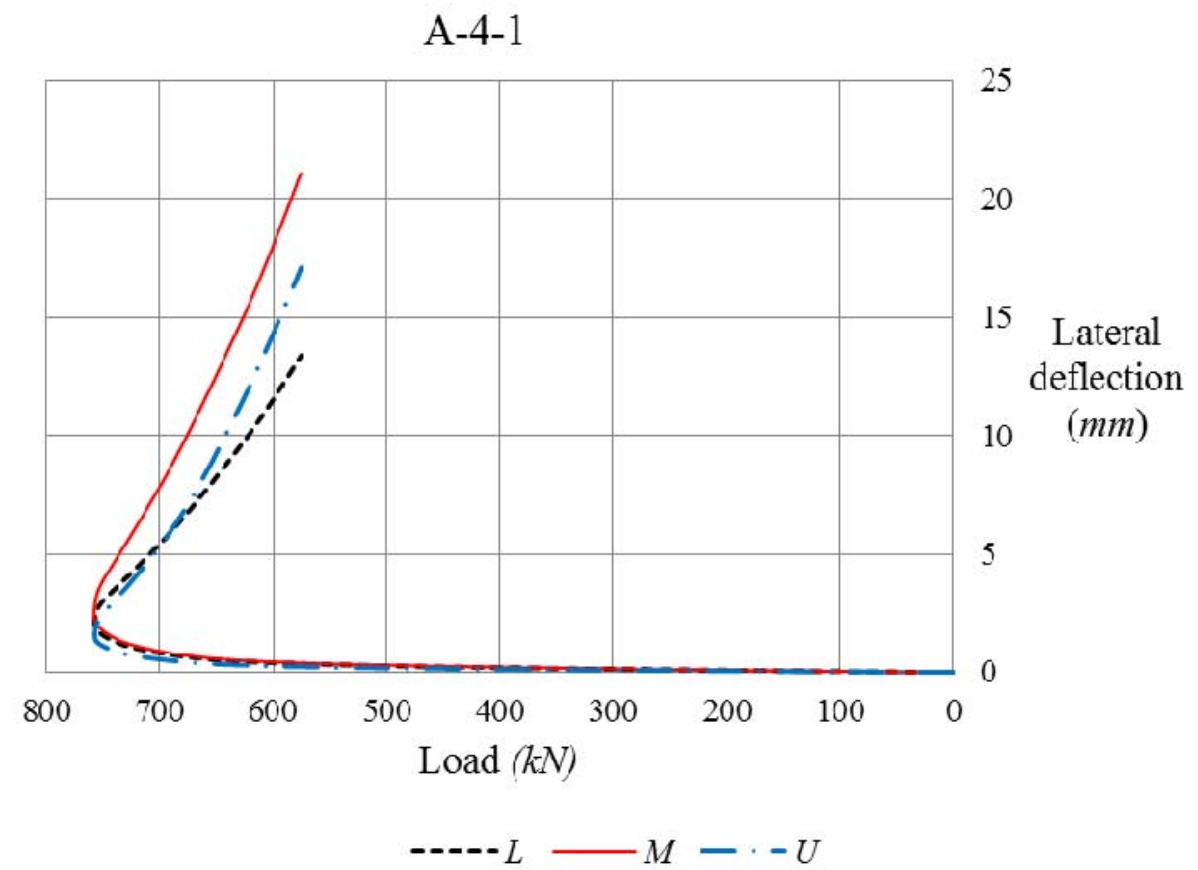

Figure 7b. Load - Lateral Deflection Curves under Patch Loading of Beams (Top from Ref. [1], bottom is result of present work)

\section{NON-LINEAR FEM ANALYSIS AND DISCUSSION}

In the following part, the effect of double side distributed pits on the ultimate capacity of beam plates with corroded web is investigated. Several research results (Saad-Eldeen et al. [26-27]) have shown that the material properties of corroded steel may change. But as mentioned before, since the load-carrying capacity ratio of corroded specimens to control specimen is investigated here, this has no effect on the present results. Therefore, the effect of corrosion on material properties has not been taken into account in this study. Figure 8 shows a typical steel web plate between flanges in an I-beam structure subjected to patch loading. The web plate and flanges length, breadth and thickness denotations are shown also in Figure 8. The geometric and material properties of the plate are as follows:

$-\left(L_{l}\right)=500 \mathrm{~mm}$

- Plate breadth $\left(L_{2}\right)=450 \mathrm{~mm}$

- Plate height $\left(h_{w}\right)=300 \mathrm{~mm}$

- Plate thickness $(t)=10 \mathrm{~mm}$

- Flange breadth $\left(b_{f}\right)=150 \mathrm{~mm}$

- Flange thickness $\left(t_{f}\right)=25 \mathrm{~mm}$

- Shape of pit corrosion= cylindrical

- Elastic modulus $(E)=205.8 \mathrm{GPa}$

- Poisson's ratio $(v)=0.3$

- Material yield stress $\left(\sigma_{y}\right)=421 \mathrm{MPa}$ 


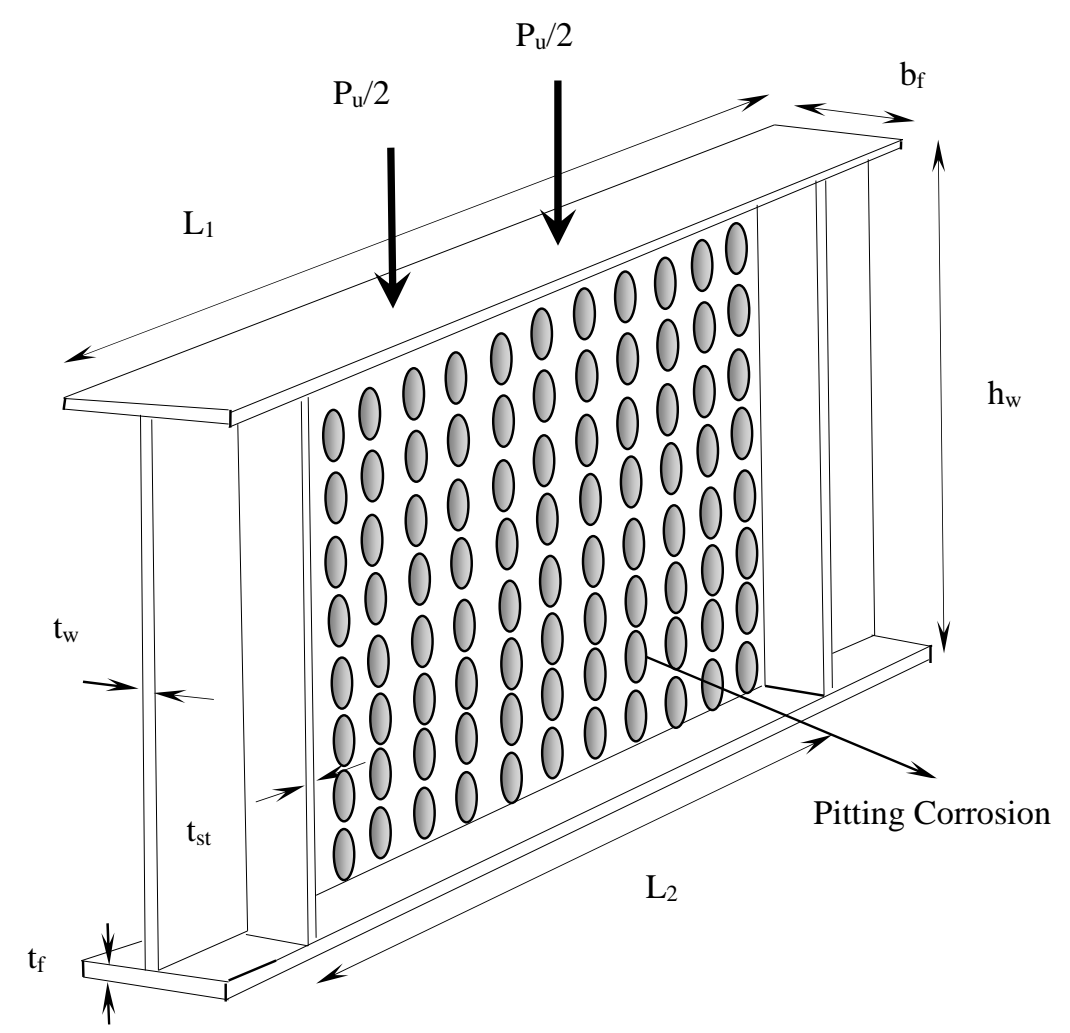

Figure 8. A Typical Model of Beam Web Plate

As stated previously, a series of nonlinear FE analyses have been conducted using ABAQUS software. The arc length method is applied to accomplish the procedure. The boundary conditions of this steel beam are as same of Figure 6b. In order to have exact simulation, shell element has been chosen. This type of element is completely suitable to simulate the real pit shape. There are several literatures that report the strain hardening has a negligible effect on the ultimate strength of steel structures (Paik et al. [4-5]). Nevertheless to simulate precisely, here steel is modeled as a J2 material with bilinear isotropic hardening and a stress-strain curve that consists of an elastic region and a strain hardening region is assumed. It has been supposed a uniform distribution pits on both sides of the web plate as can be seen from Figure 8. The shape of pit corrosion is supposed cylindrical with ratio of pit diameter to its depth 8. The pit corrosion characteristics have been shown in Table 2. As can be seen from this Table, the range of DOP is between $0-59.72 \%$. It should be mentioned here that by employing the ratio of pit diameter to its depth as 8 , the maximum DOP will be $59.72 \%$.

Figures 9 show deflected shapes of beam web plates with various pit corrosion intensities immediately after the ultimate strength is reached. The loads in ultimate state have been summarized in Table 3. The load-carrying capacitates of damaged steel beams for each DOP has been also shown in this Table. As it was expected, the capacity with increasing DOP is decreased. It should be noted here that, this trend is not similar for maximum axial shortening and lateral deflection. This is attributed to the fact that the localized plasticity develops in different increments due to the unevenness behavior of pit corrosion elements. Figures 10 and 11 show the patch loads versus vertical deflection and maximum lateral deflections curves for all beams with different damaged corrosion intensities. It is obvious that ultimate load and deformation behaviors are strongly affected by pit corrosion intensities. As the analyses increments have been kept constant during the nonlinear evaluations by software, it can be found from Figures 10 and 11 that the specimens with higher DOP give more deformability compare to specimens with lower DOP. 
Table 2. Artificial Pitting in Structural Models

\begin{tabular}{ccccc}
\hline Model No. & $\begin{array}{c}\text { Pit diameter } \\
(\mathrm{mm})\end{array}$ & $\begin{array}{c}\text { Pit depth } \\
(\mathrm{mm})\end{array}$ & $\begin{array}{c}\text { Number } \\
\text { of pits }\end{array}$ & $\begin{array}{c}\text { Ratio of pit } \\
\text { diameter } \\
\text { to depth }\left(d_{p} / h_{p}\right)\end{array}$ \\
\hline Dop=0.00\% (Intact) & 0 & 0 & 0 & 0 \\
\hline Dop $=0.66 \%$ & 8 & 1 & 88 & 8 \\
\hline Dop $=5.24 \%$ & 16 & 2 & 88 & 8 \\
\hline Dop $=10.24$ & 20 & 2.5 & 88 & 8 \\
\hline Dop $=17.69$ & 24 & 3 & 88 & 8 \\
\hline Dop=28.1 & 28 & 3.5 & 88 & 8 \\
\hline Dop $=34.56$ & 30 & 3.75 & 88 & 8 \\
\hline Dop $=41.94$ & 32 & 4 & 88 & 8 \\
\hline Dop $=50.31$ & 34 & 4.25 & 88 & 88 \\
\hline Dop $=59.72$ & 36 & 4.5 & & 88 \\
\hline
\end{tabular}

$d_{p}=$ Pit diameter

$h_{p}=$ Pit depth

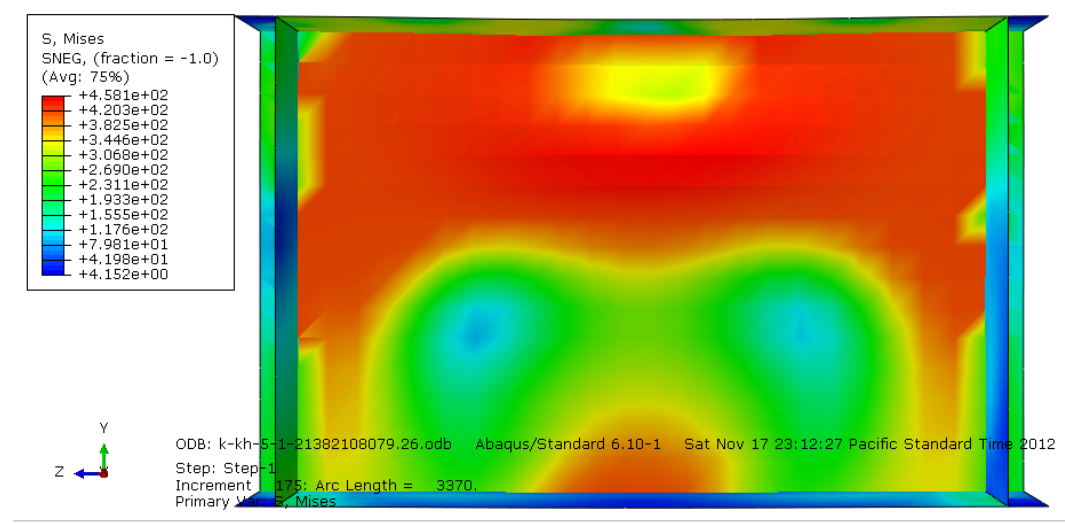

a)

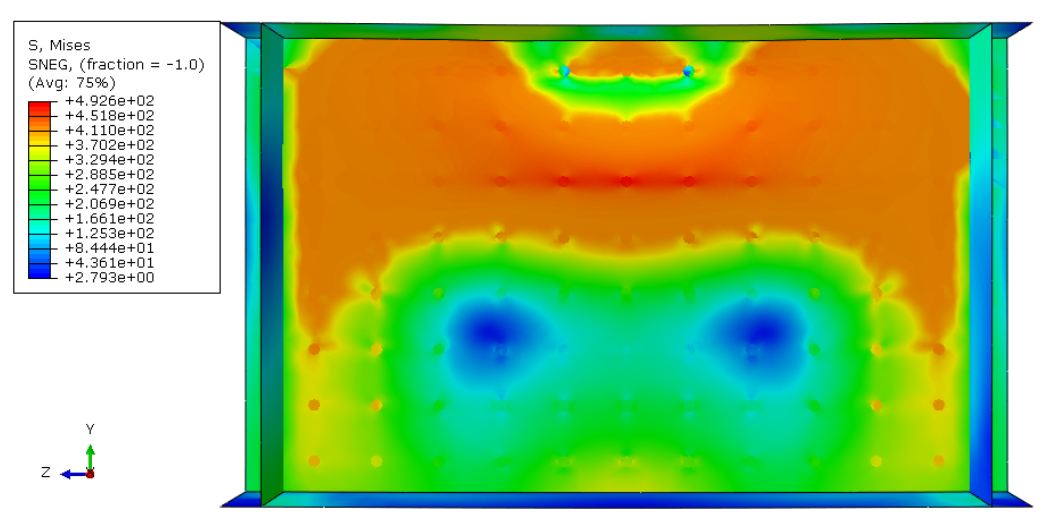

b) 

Subjected to Patch Loading by Artificial Neural Networks

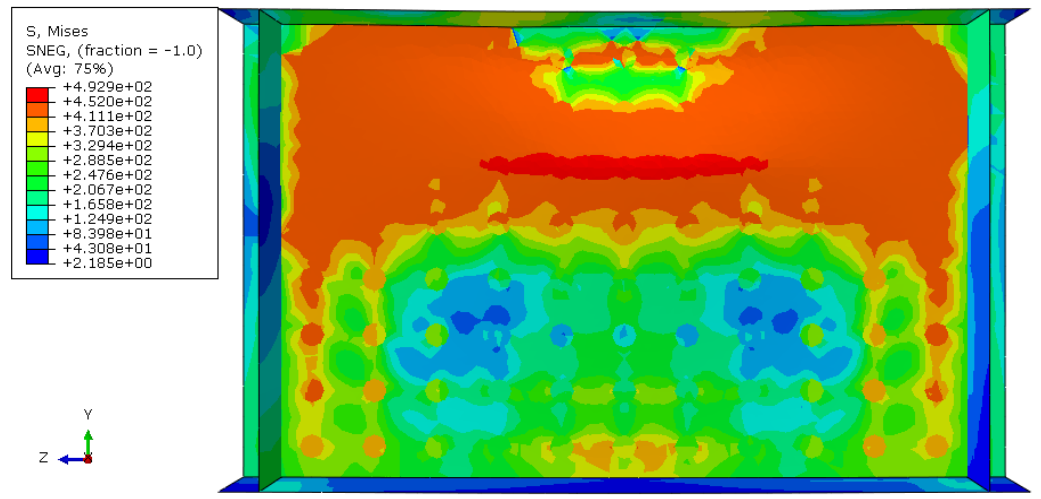

c)

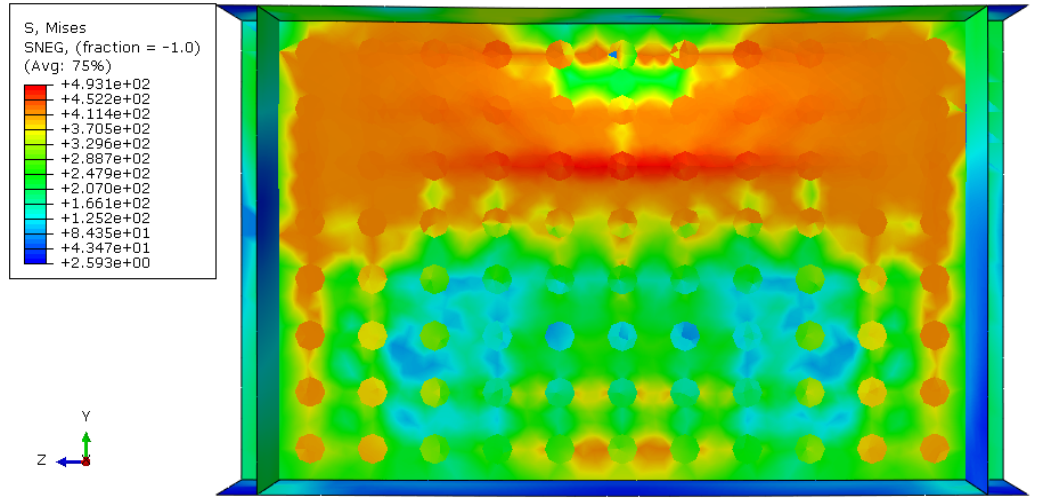

d)

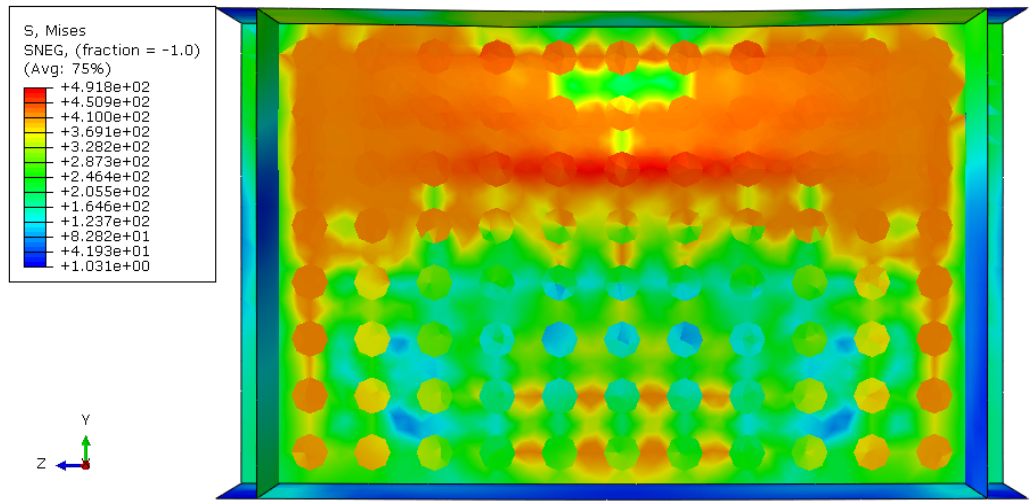

e) 


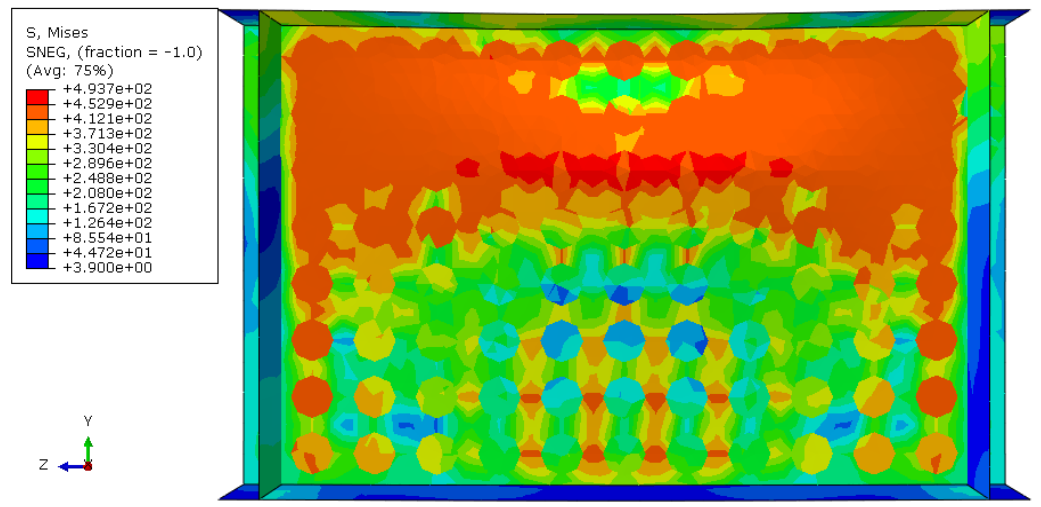

f)

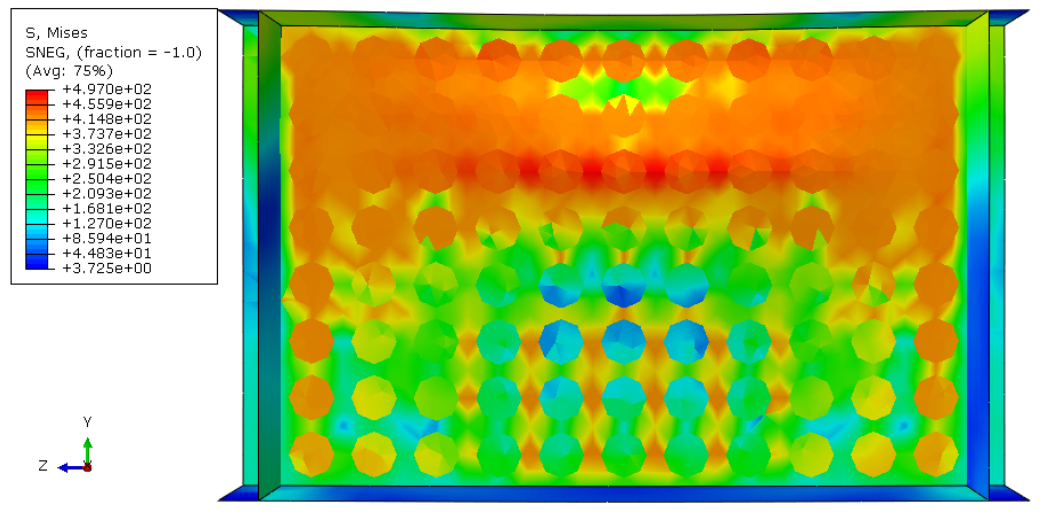

g)

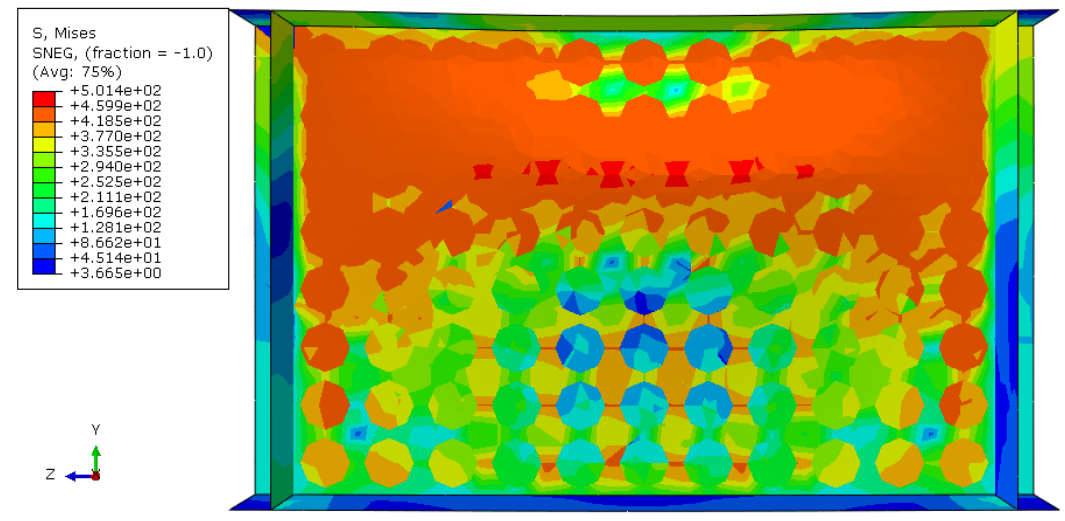

h) 


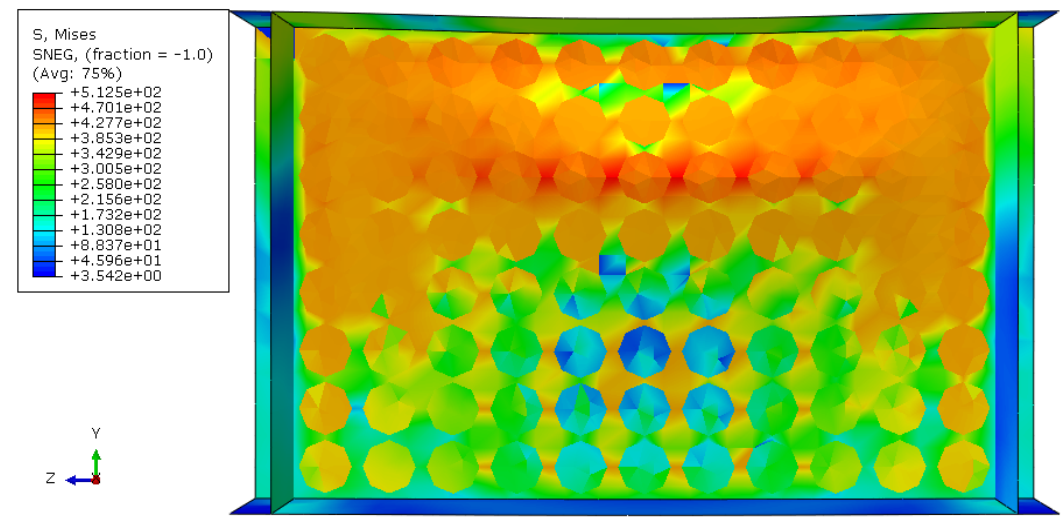

i)

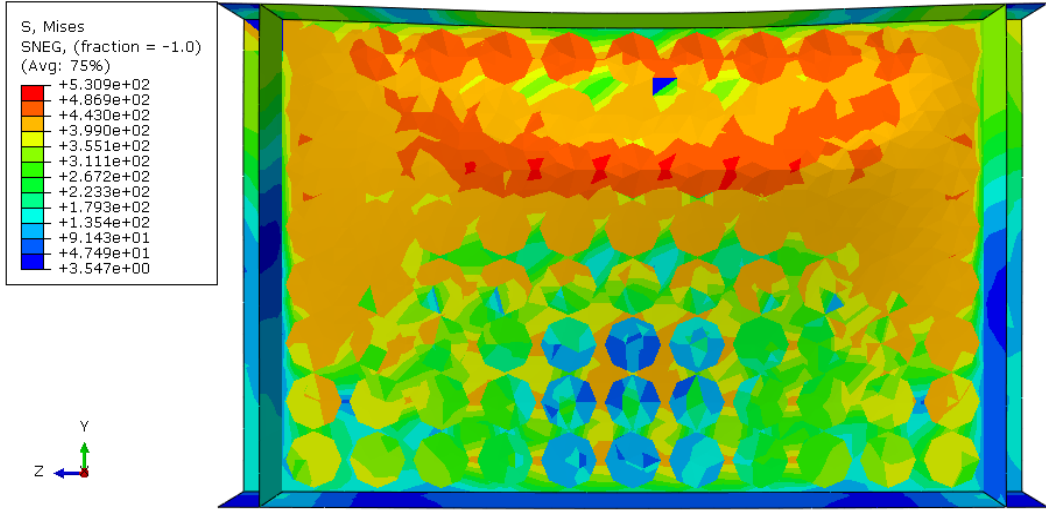

j)

Figure 9. Deformation and the Von Mises Stress Distribution on Mid-Surface of a Pitted Beam Web Plate under Patch Loading, with Varying Level Of DOP at the Ultimate Strength, as Obtained by ABAQUS: (a) Intact; (b) DOP 0.66\%; (c) DOP 5.24\%; (d) DOP 10.24\%; (e) DOP 17.69\%; (f) DOP 28.1\%; (g) DOP 34.56\%; (h) 41.94\%; (i) DOP 50.31\%; (j) DOP 59.72\%.

Table 3. FE Ultimate Strength Results of Models

\begin{tabular}{ccc}
\hline Model No. & $P_{u}$ & $P_{u} / P_{u 0}$ \\
\hline Dop=0.00\% (Intact) & 1377.062 & 1 \\
\hline Dop=0.66\% & 1362.77 & 0.99 \\
\hline Dop=5.24\% & 1256.87 & 0.91 \\
\hline Dop=10.24 & 1156.72 & 0.84 \\
\hline Dop=17.69 & 1029.94 & 0.75 \\
\hline Dop=28.1 & 880.7 & 0.64 \\
\hline Dop=34.56 & 803.07 & 0.58 \\
\hline Dop=41.94 & 734.87 & 0.53 \\
\hline Dop=50.31 & 656.97 & 0.48 \\
\hline Dop=59.72 & 573.36 & 0.42 \\
\hline$P_{u o}=$ Ultimate strength of intact model \\
$P_{u}=$ Ultimate strength of corroded models
\end{tabular}




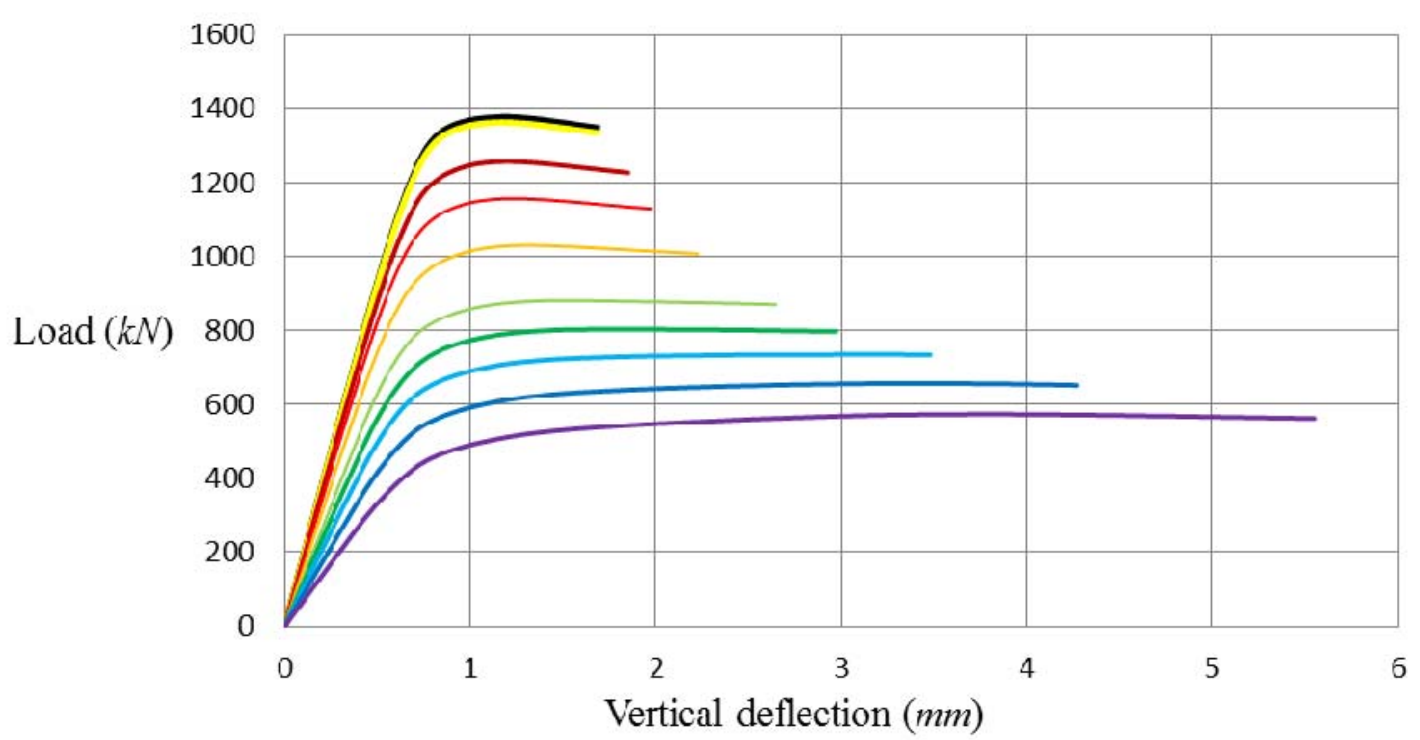

$-\mathrm{DOP} \%=0 \quad \mathrm{DOP} \%=0.66-\mathrm{DOP} \%=5.24-\mathrm{DOP} \%=10.24-\mathrm{DOP} \%=17.69$
$\mathrm{DOP} \%=28.1-\mathrm{DOP} \%=34.56-\mathrm{DOP} \%=41.94-\mathrm{DOP} \%=50.31-\mathrm{DOP} \%=59.72$

Figure 10. Load - Vertical Deflection Curves for Specimens with Different Corrosion Intensities

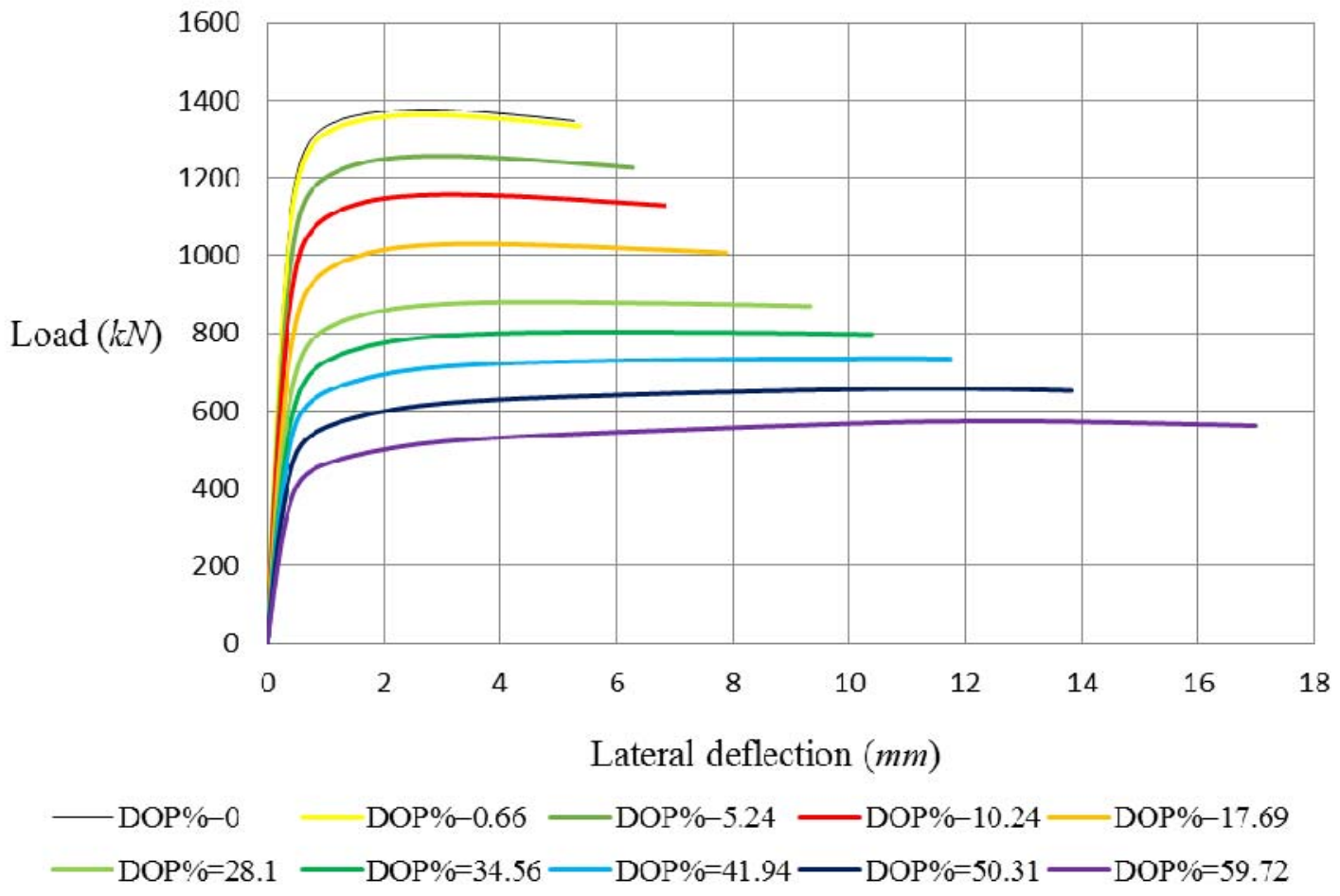

Figure 11. Load - Maximum Lateral Deflection Curves for Specimens with Different Corrosion Intensities 


\section{ULTIMATE STRENGTH FORMULAE}

In case of members with pitting corrosion, which has large unevenness on the surface the evaluation of residual strength is considered to be difficult. In the above-mentioned analyses, rather a complicated method of modeling pitted members is employed. For a practical purpose, a simpler method is desired. In practical application it is desirable to predict a pitted corrosion surface by a surface that is corroded uniformly. This is for the reason that all rules and regulations concerning strength of corroded based-plate structures are based on uniform thickness reduction, and there are several formulations to estimate the ultimate strength of a shape -plate member as a function of thickness. Therefore, in the present paper the attempt is to simulate a pitted corroded web beam with different DOP, with a uniform decreased thickness one.

The load carrying capacity of damaged pitting and uniform corrosion web plate beam has been shown in Figures 12 and 13, respectively. Both of them have been concluded from the obtained results of software. In other word, the thickness of the web plate has been decreased step by step uniformly, and then its residual strength as well as pitted specimens was examined and shown in Figures 12 and 13. The ratio of the ultimate strength to ultimate strength of intact specimen for both pitting corrosion and uniform corrosion has been developed by formulae. It is evident that the web plate beam ultimate strength under patch loading is significantly decreased as the level of DOP increases. The ultimate strength reduction factor for a web plate beam with pit corrosion can be expressed by ANNs of the computed results as a function of the DOP. In this study, the BP network is employed for predicting beam ultimate strength with web pitting corrosion under patch loading. In the next subsection, the theoretical background of the computational methods is briefly explained. As the reduction strength of damaged beams with web uniform corrosion give a semi-linear results, the regression analysis gives the exact and reasonable output.

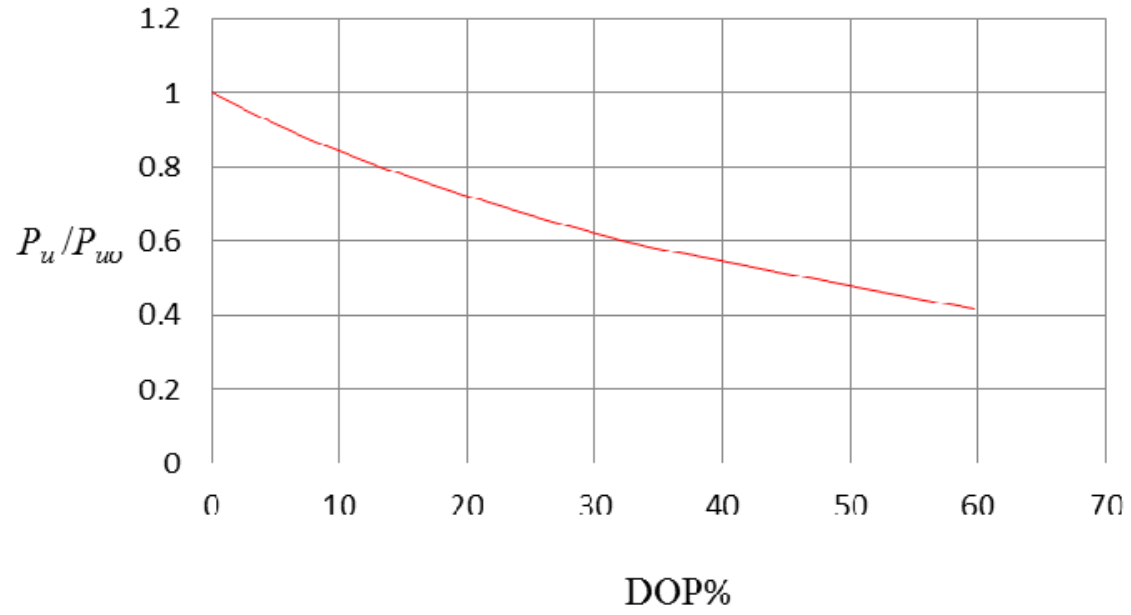

Figure 12. The Ultimate Strength Versus the DOP Ratio for a Steel Web Plate with Pit Corrosion under Patch Loading ( $P u, P u$ are ultimate strengths for pitted and intact plates, respectively) 


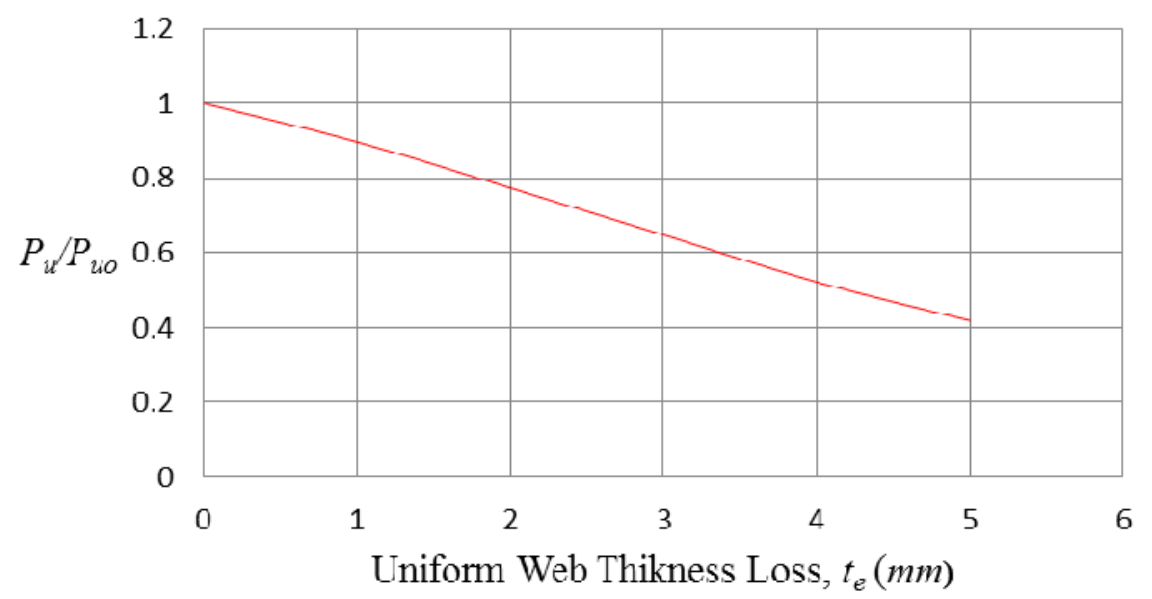

Figure 13. The Ultimate Strength Versus the Web Loss Thickness for a Steel Web Plate with Uniform Corrosion under Patch Loading $\left(P_{u}, P_{u o}\right.$ are ultimate compressive strengths for uniform loss thickness and intact plates, respectively)

\subsection{ANN Approach}

\subsubsection{Introduction}

A neural network is a massively parallel distributed processor that has a natural propensity for storing experiential knowledge and making it available for use (Haykin [28]). An ANN is a mathematical model that tries to simulate the structure and functionalities of biological neural networks. Basic building block of every artificial neural network is artificial neuron, that is, a simple mathematical model. The Multilayer Perceptron (MLP) procedure produces a predictive model for one or more dependent (target) variables based on the values of the predictor variables. The structure of an MLP consists of the neurons are organized in layers, which are usually fully connected by synapses. A synapse can only connect to subsequent layers. To each of the synapses, a weight is attached indicating the effect of the corresponding neuron. The Multilayer Perceptron (MLP) is the feed forward architecture because the connections in the network flow forward from the input layer to the output layer without any feedback loops. Feed forward networks often have one or more hidden layers of sigmoid neurons followed by an output layer of linear neurons. Multiple layers of neurons with nonlinear transfer functions allow the network to learn nonlinear relationships between input and output vectors. The linear output layer is most often used for function fitting (or nonlinear regression) problems (Neural Network Toolbox [29]).

The back propagation algorithm is used in layered feed forward ANNs. This means that the artificial neurons are organized in layers, and send their signals "forward", and then the errors are propagated backwards (Rumelhart [30]). The back propagation algorithm is used for multilayered networks and is a supervised learning process. Supervised learning is the most typically neural network setting. These learning algorithms are characterized by the usage of a given output that is compared to the predicted output and by the adaptation of weights according to this comparison. The back propagation algorithm is used to minimize the simulation error until the network converges to the expected performance function. Back propagation looks for the error function minimum in the weight space by applying the gradient descent method (Rojas [31]). Define the error function for the output of neural network: 


$$
\varepsilon^{2}=(\text { traget }- \text { OUTPUT })^{2}
$$

where $\varepsilon$ is error, target is dependent variables and OUTPUT is network outputs.

The Multilayer Perceptron (MLP) represents a useful neural network approach for predicting strength of structures. Pu and Mesbahi [32] have proposed a formula for predict ultimate strength of plates using ANN. Hajela and Berke [33] used back propagation neural network to represent the force displacement relationship in static structural analysis. Ok et al. [34] have proposed formulae that can accurately predict the ultimate strength of locally corroded plates under uniaxial in-plane compression. Guzelbey et al. [35] employed back-propagation neural network for estimation of available rotation capacity of wide flange beams. Fonseca et al. [11] predicted steel beam patch load resistance using back-propagation network. Fonseca et al. [36] have also carried out parametric studies based on the neural network model, and furthermore they have proposed a neuro-fuzzy system for the parametric analysis of patch load resistance (Fonseca et al. [37]). On the other hand, Cevik [38] has recently proposed a genetic programming-based formulation for load resistance. Gholizadeh et al. [39] employed back-propagation neural network for predict the load carrying capacity of the castellated steel beams. In this study, the back-propagation network and MLP are employed for predicting the load carrying capacity of damaged steel beams with web pitting corrosion subjected to patch loading.

\subsubsection{ANN Structure}

Input vector which has been selected for this proposed model is as $\left\{X_{1}=D O P\right\}$. It is desired to assess the ultimate capacities of steel beams with damaged web plate with different pitting corrosion intensities under patch loading. Using obtained FE results the input vector, $X_{1}=D O P$, has ten different values ranging from 0 (for intact specimen) to 59.72 (for maximum damaged specimen). Accordingly, the output vector for the neural network model is selected as $\left\{P_{u} / P_{u o}\right\}$. There is no direct method to select number of nodes in hidden layers. Generally a trial and error method is adopted for arriving at the network configuration. After doing a few trials, it is observed that the network has two hidden layer because this kind of model has been found to have sufficient accuracy and less demand on the amount of training data. There are three neurons in the input layer, e.g. $X_{1}$. Also the number of neurons in output layer is equal to one. Each input is weighted with an appropriate $w$. The sum of the weighted inputs and the bias forms the input to the transfer function $f$. Neurons can use any differentiable transfer function $f$ to generate their output. The neural network's configuration shown in Figure 14.

The network that is used for this study is a three-layer feed forward network, with hyperbolic tangent transfer functions in the hidden layer and identity transfer functions in the output layer. The outputs using a logistic activation function can be expressed as

$$
\frac{P_{u}}{P_{u 0}}=\left|W_{3} \times\left(\tanh \left(W_{2} \times\left[\begin{array}{c}
1 \\
\tanh \left(W_{1} \times X\right)
\end{array}\right]\right)\right)\right|
$$

where

$$
W_{1}=\left[\begin{array}{ccc}
1 & b_{A 1} & W_{1, A 1} \\
\vdots & & \\
\vdots & b_{A 2} & W_{1, A 2} \\
\vdots \\
1 & b_{A 3} & W_{1, A 3}
\end{array}\right],
$$




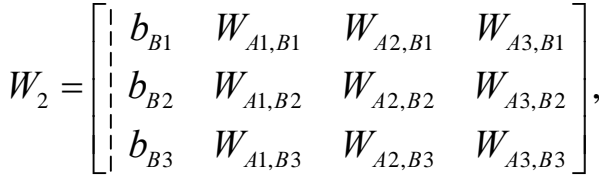

$$
\begin{aligned}
& W_{3}=\left[\begin{array}{llll}
b_{\text {out }} & W_{B 1, \text { uot }} & W_{B 2, \text { out }} & W_{B 3, \text { out }}
\end{array}\right] \text {, } \\
& X=\left[\begin{array}{ll}
1 & x_{1}
\end{array}\right]^{T} \text {. }
\end{aligned}
$$

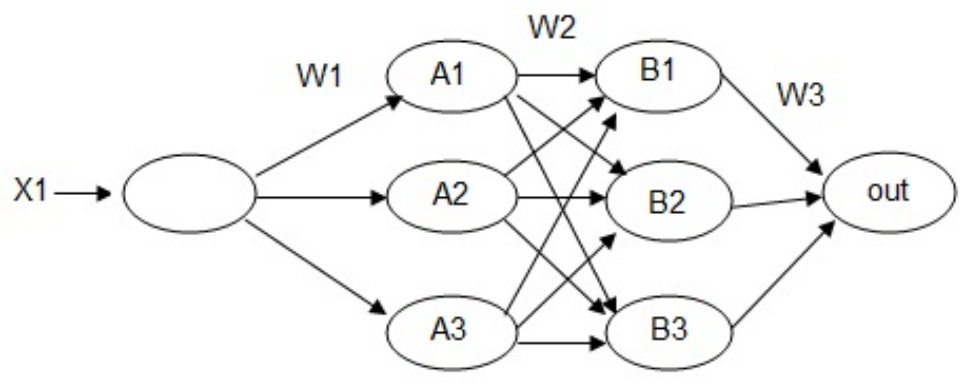

Figure 14. Structure of the Multi-Layer Feed forward Network

\subsubsection{Training and Testing of the Network}

Back propagation algorithm is used in layered feed forward ANNs for training in present study. During the training procedure, the input and desired data will be repeatedly presented to the network. As the network learns more and more, the error tends to drop towards zero. Updates the weights after passing all training data records, it is most useful for small datasets. The maximum number of epochs is equal to 10000 . If the maximum number of epochs is exceeded, then training stops.

\subsubsection{Residual Patch Loading Strength Assessment of Damaged Steel Beams with Pitting Corrosion}

The ultimate capacity reduction factor $(\mu)$ for the deteriorated steel beams web plate with pitting corrosion may be expressed by ANN of the obtained FE results as a function of DOP, as follows:

$\mu=\frac{P_{u}}{P_{u o}}$

where $P_{u o}$ is the ultimate strength for the perfect (i.e., without pit) specimen and $P_{u}$ is the capacity of damaged beams with different pitting corrosion intensities subjected to patch loading. The derived formula based ANN for predicting strength reduction is expressed as:

$$
\begin{aligned}
& \mu=\left|W_{3} \times\left(\tanh \left(W_{2} \times\left[\begin{array}{c}
1 \\
\tanh \left(W_{1} \times X\right)
\end{array}\right]\right)\right)\right| \\
& X=\left[\begin{array}{ll}
1 & D O P
\end{array}\right]^{T},
\end{aligned}
$$




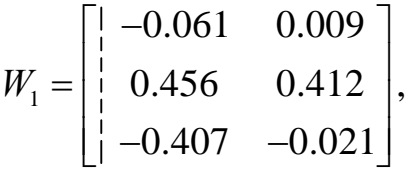

$$
\begin{aligned}
& W_{2}=\left[\begin{array}{ccccc}
1 & -0.572 & 0.235 & -0.3 & -0.377 \\
1 & 0-.456 & 0.499 & -0.407 & 0.176 \\
1 & 0-.381 & 0.51 & 0.236 & -0.616
\end{array}\right], \\
& W_{3}=\left[\begin{array}{llll}
0.459 & -0.518 & -0.344 & -0.815
\end{array}\right] \text {. }
\end{aligned}
$$

and then the derived remaining capacity of deteriorated beams $\left(P_{u}\right)$ formula has been expressed as:

$$
P_{u}=\mu \times P_{u o}
$$

Table 4 shows summary of the neural network results along with error, relative error or percentage of incorrect predictions, and the training time. Regression analysis of the network outputs and desired outputs (targets) are then carried out to characterize the network accuracy. Figure 15 shows the correlation of both FEM results and ANN outputs. The results are accurate with a mean value of 1. It is evident from Figure15 that neural network is valid for predicting the ultimate residual strength of damaged beams with corroded web subjected to patch loading.

\begin{tabular}{|c|c|c|}
\hline \multirow{5}{*}{ Training } & Sample & $70 \%$ \\
\hline & Number of epochs & 10000 \\
\hline & Sum of Squares Error & $1.055 \mathrm{E}-7$ \\
\hline & Relative Error & $8.13 \mathrm{E}-7$ \\
\hline & Training Time & $0.019 \mathrm{sec}$ \\
\hline \multirow{3}{*}{ Testing } & Sum of Squares Error & $8.45 \mathrm{E}-5$ \\
\hline & Sample & $30 \%$ \\
\hline & Relative Error & 0.002 \\
\hline
\end{tabular}

Table 4. Summary of the Neural Network Results for Predict Strength of Beam under Patch Loading

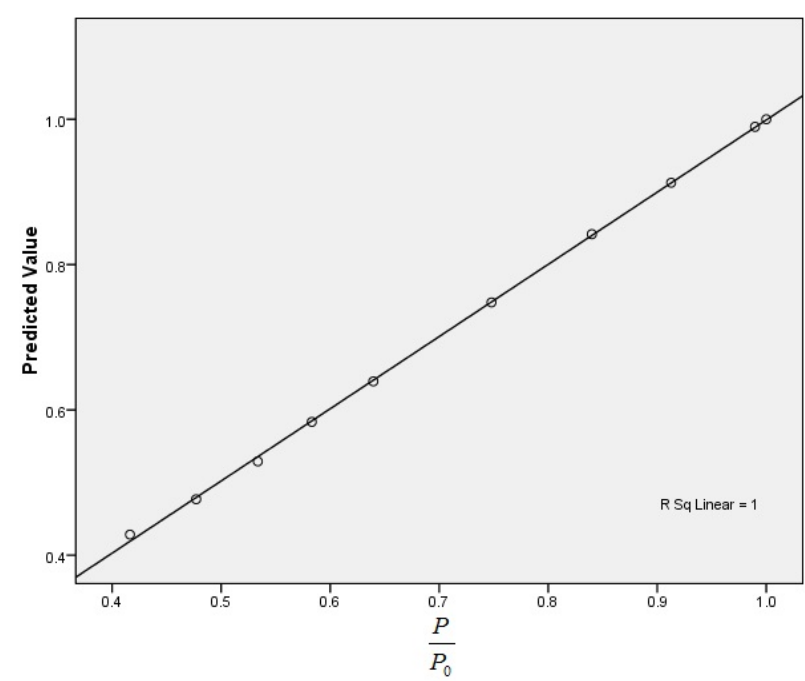

Figure 15. Correlation of FEM Results and ANN Outputs for Ultimate Strength of Beam Web Plate with Pitting Corrosion 
It is evident from Figure 16, that Equation 18 is valid for predicting the ultimate strength of a steel web plate with pitting corrosion.

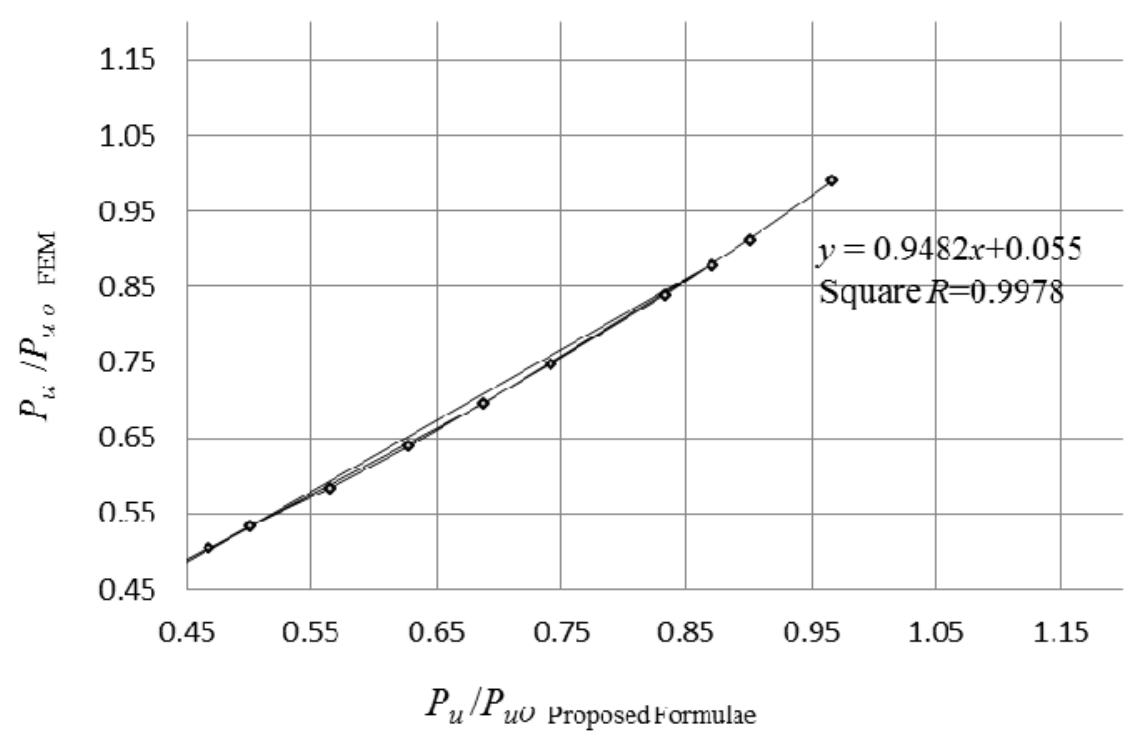

Figure 16. Accuracy of the Proposed Formulae, Equation 18, for the Ultimate Strength Prediction of a Pitted Steel Beam Web Plate with Equivalent Uniform Thickness Loss and under Compressive Loads

\subsection{Residual Patch Loading Strength Assessment of Damaged Steel Beams with Uniform Corrosion}

It was found that the relationship between the residual capacities of damaged steel plate structures with uniform corrosion is linear (Figure 13), approximately. Therefore, in order to assess the reduction factor formula the ANN and regression approaches give an equal formulation with same accuracy. In this reason the ultimate capacity reduction factor for a damaged web plate beam with uniform corrosion has been expressed by the regression analysis of the obtained FE results as a function of the uniform thickness loss $\left(t_{e}\right)$, as follows:

$\frac{P_{u}}{P_{u o}}=-0.119 \times t_{e}+1.007, \quad t_{e}>0$

$P_{u}, P_{u o}$ are ultimate strengths for corroded and intact beam web plates, respectively, $t_{e}$ is the uniform web thickness loss.

\subsection{Simulation of DOP with an Equivalent Uniform Thickness Loss for Corroded Web Plate Beams in Term of Ultimate Capacity}

For general corrosion, which uniformly reduces plate thickness, the plate ultimate strength calculations are typically carried out excluding the thickness loss due to corrosion. For pitting corrosion the strength calculation procedure can be more complex, and for a simplified pessimistic treatment, the corroded plates have been idealized using an equivalent general corrosion. Therefore, for a practical purpose, the equivalent uniform thickness can be an appropriate parameter for the evaluation of the beam capacity of pitted web plates. In this section the effort is to simulate damaged pit corrosion web beams with beams those webs are corroded uniformly by comparing 
those ultimate capacities. Equations 18 and 19 summarize the computed results of the remaining ultimate strengths as a function of DOP and uniform thickness loss $\left(t_{e}\right)$. As mentioned, the aim is to represent the pitted web plate beam with a beam that its web thickness is decreased uniformly on all over web surface. Therefore, a formula for simulating DOP to uniform thickness loss can be also derived by fitting curves. Equation 20 presents the equivalent thickness loss as function of pitting corrosion intensities in term of ultimate capacity.

$t_{e}=t_{w}-t_{r}=9.4622-8.40336 \times \mu_{p i t}$

where, $t_{e}, t_{w}$, and $t_{r}$ are the uniform web thickness loss, initial web thickness and remaining uniform web thickness, respectively. $\mu_{p i t}$ is the reduction strength in term of pitting corrosion which is just function of DOP based Equation 16.

\section{CONCLUSIONS}

The potential for the structural capability degrading effects of corrosion is of profound importance and must be fully understood and reflected in vessel's inspection and maintenance programme. Corrosion has been studied and quantified by many researchers, however its effect on structural integrity is still subject to uncertainty, particularly with regards to localized corrosion. In the present study, for the purpose of investigating the effect of pitting corrosion on ultimate strength of web plate beams subjected to patch loading, a series of ABAQUS elastic-plastic large deflection finite element analyses were carried out, varying the pit corrosion intensities. Obviously the ultimate strength of a web plate beam can be significantly decreased due to pit corrosion as well as general corrosion. In the present study, the ultimate strength reduction factor due to pitting corrosion is empirically derived by Artificial Neural Networks (ANNs) of the obtained FE results as a function of DOP. The ANN based empirical formulae show excellent accuracy to predict the residual strength reduction of corroded web plates beams with pitting corrosion under patch loading. The results and insights developed in the present study will be very useful for damage tolerant design of steel beam structures that are constructed in a very corrosive environment. The beam plate ultimate strength design formulae developed can be utilized for the ultimate limit state based reliability or risk assessment of beam plated structures with web pit corrosion wastage.

While ultimate capacity of a plate element subjected to different loads and boundary conditions with uniform corrosion can be calculated by excluding the thickness loss due to corrosion, predicting the ultimate capacity of a pitted plate is not a simple manner as well as uniform corrosion. It is desired to simulate damaged steel structures with pit corrosion wastage with an equivalent structure which corroded uniformly in term of strength. For a practical purpose, the equivalent uniform thickness can be an appropriate parameter for the evaluation of the beam behavior of pitted web plates. Therefore, based the obtained results of FEM and ANNs a practical formulae for predicting a damaged web pitted plate beam with a measured DOP with a beam that its web corroded uniformly is also developed.

\section{ACKNOWLEDGEMENTS}

The authors are pleased to acknowledge the Vali-e-Asr University of Rafsanjan support. 


\section{REFERENCES}

[1] Nakai, T., Matsushita, H. and Yamamoto, N., "Effect of Pitting Corrosion on Strength of Web Plates Subjected to Patch Loading”, Thin-Walled Structures, 2006, Vol. 44, pp. 10-19.

[2] Nakai, T., Matsushita, H., Yamamoto, N. and Hironori A., "Effect of Pitting Corrosion on Local Strength of Hold Frames of Bulk Carriers (1st report)”, Thin-Walled Structures, 2006, Vol. 44, pp. 10-19.

[3] Nakai, T., Matsushita, H. and Yamamoto, N., "Effect of Pitting Corrosion on the Ultimate Strength of Steel Plates Subjected to In-Plane Compression and Bending”. Journal of Marine Science and Technology, 2006, Vol. 11, No. 1, pp. 52-64.

[4] Paik, J.K., Lee, J.M. and Ko, M.J., "Ultimate Compressive Strength of Plate Elements with Pit Corrosion Wastage”, Journal of Engineering Maritime Environment, 2003, Vol. 217, No. M4, pp. 185-200.

[5] Paik, J.K., Lee, J.M. and Ko, M.J., "Ultimate Shear Strength of Plate Elements with Pit Corrosion Wastage”, Thin-Walled Structures, 2004, Vol. 42, No. 8, pp. 1161-76.

[6] Sharifi, Y. and Paik, J.K., "Ultimate Strength Reliability Analysis of Corroded Steel-box Girder Bridges”, Thin-Walled Structures, 2011, Vol. 49, No. 1, pp. 157-166.

[7] Sharifi, Y. and Paik, J.K., "Environmental Effects on Ultimate Strength Reliability of Corroded Steel Box Girder Bridges”, Structural Longevity, 2010, Vol. 18, No. 1, pp. 1-20.

[8] Sharifi, Y., "Reliability of Deteriorating Steel Box-Girder Bridges under Pitting Corrosion”, Advanced Steel Construction, 2011, Vol. 7, No. 3, pp. 220-238.

[9] Sharifi, Y. and Tohidi, S., "Lateral-torsional buckling capacity assessment of web opening steel girders by artificial neural networks-elastic investigation”, Frontiers of Structural and Civil Engineering, 2014, Vol. 8, No. 2, pp. 167-177.

[10] Nethercot, D.A., "Limit States Design of Structural Steelwork”, 3rd ed. London, UK: Spon Press, 2001.

[11] Adeli, H., Hung, S.L., "Machine Learning: Neural Networks, Genetic Algorithms, and Fuzzy Systems”, New York, Wiley, 1995.

[12] Fonseca, E.T., Vellasco, P.C.G., Andrade, S.A.L. and Vellasco, M.M.B.R., "Neural Network Evaluation of Steel Beam Patch Load Capacity”, Advances in Engineering Software, 2003, Vol. 34, pp. 763-72.

[13] Jang, J.S.R., “ANFIS: Adaptive-Network-Based Fuzzy Inference Systems”, IEEE Transactions on Systems, Man and Cybernetics, 1993, Vol. 23, pp. 665-85.

[14] Hagan, M.T. and Menhaj, M., "Training Feed-Forward Networks with the Marquardt Algorithm”, IEEE Transactions on Neural Networks, 1999, Vol. 5, pp. 989-93.

[15] Guzelbey IH, Cevik bA, Gogus MT. Prediction of rotation capacity of wide flange beams using neural networks. Journal of Constructional Steel Research 2006; 62:950-61.

[16] EN 1993-1-1 Eurocode 3: Design of Steel Structures, Part 1.1 General Rules and Rules for Buildings, British Standard Institution, London 2005.

[17] Paik, J.K. and Thayamballi, A.K., "Ultimate Limit State Design of Steel-Plated Structures”, John Wiley \& Sons, Ltd., Hoboken, New Jersey, USA, 2003.

[18] Dogaki, M., Yonezawa, H. and Tanabe, T., "Ultimate Strength of Plate Girders with Longitudinal Stiffeners under Patch Loading”, Proceedings of the $3^{\text {rd }}$ Pacific Structural Steel Conference, The Japan Society of Steel Construction, Tokyo, 26-28 October, 1992, pp. 507-514.

[19] Dogaki, M., Nishijima, Y. and Yonezawa, H., "Nonlinear Behaviour of Longitudinally stiffened Webs in Combined Patch Loading and Bending”, Constructional Steel Design: World Developments, Elsevier Applied Science 1992, London, pp. 141-150.

[20] Takimoto, T., "Plate Girders under Patch Loading”, Ultimate Strength and Design of Steel Structures, The Japan Society of Civil Engineers, Tokyo 1994, pp. 122-127 (in Japanese).

[21] Roberts, T.M. and Rockey, K.C., “A Mechanism Solution for Predicting the Collapse Loads 
of Slender Plate Girders when Subjected to In-Plane Patch Loading”, Proc Inst Civ Eng Struct Build, 1979, Vol. 67, No. 2, pp. 155-75.

[22] Bergfelt, A., "Patch Loading On a Slender Web-Influence of Horizontal and Vertical Web Stiffeners on the Load Carrying Capacity”, Chalmers University of Technology, Dept. of Structural Engineering, Div. of Steel and Timber Structures, Publ. S79:1, Goteborg, 1979.

[23] Eurocode 3: Design of Steel Structures, Part 1-5: General Rules, Supplementary Rules For Planar Plated Structures without Transverse Loading, ENV 1993-1-5:1997 E, 2006.

[24] Lagerqvist, O. and Johansson, B., "Resistance of I-Girders to Concentrated Loads”, Journal of Constructional Steel Research, 1996, Vol. 39, No. 2, pp. 87-119.

[25] ABAQUS user's manual, version 6.9. Pawtucket, RI: Hibbit, Karlsson \& Sorenson, 2005.

[26] Saad-Eldeen, S., Garbatov, Y. and Guedes Soares, C., "Compressive Strength Assessment of a Moderately Corroded Box Girder”, Marine Systems and Ocean Technology, 2011, Vol. 6, pp. 27-33.

[27] Saad-Eldeen, S., Garbatov, Y. and Guedes Soares, C., "Experimental Assessment of the Ultimate Strength of a Box Girder Subjected to Severe Corrosion”, Marine Structures, 2011, Vol. 24, pp. 338-57.

[28] Haykin, S., “Neural Networks: a Comprehensive Foundation”, 2nd ed. New York: Macmillan College Publishing; 1998.

[29] Neural Network Toolbox 7 User's Guide, Mark Hudson Beale Martin T. Hagan Howard B. Demuth, 2010.

[30] Rumelhart, D. and McClelland, J., "Parallel Distributed Processing”, MIT Press, Cambridge, Mass; 1986.

[31] Rojas, R., “Neural Networks- A Systematic Introduction Springer- Verlag”, 1996.

[32] Pu, Y. and Mesbahi, E., "Application of Artificial Neural Networks to Evaluation of Ultimate Strength of Steel Panels”, Engineering Structures, 2006, Vol. 28, pp.1190-1196.

[33] Hajela, P. and Berke, L. "Neurobiological Computational Models in Structural Analysis and Design”, Computers and Structures, 1991, Vol. 41, No. 4, pp. 657-667.

[34] Ok, D., Pu, Y. and Incecik, A., "Artificial Neural Networks and Their Application to Assessment of Ultimate Strength of Plates with Pitting Corrosion”, Ocean Engineering, 2006, Vol. 34, pp. 2222-2230.

[35] Guzelbey, I.H., Cevikb, A. and Gogus, M.T., "Prediction of Rotation Capacity of Wide Flange Beams Using Neural Networks”, Journal of Constructional Steel Research, 2006, Vol. 62, pp. 950-61.

[36] Fonseca, E.T., Vellasco, P.C.S., Andrade, S.A.L. and Vellasco, M.M.B.R. "A Patch Load Parametric Analysis using Neural Networks”, Journal of Constructional Steel Research, 2003, Vol. 59, No. 2, pp. 251-67.

[37] Fonseca E.T., Andrade, S.A.L. and Vellasco, P.C.G.D., “A Parametric Analysis of the Patch Load Behaviour using a Neuro-Fuzzy System”, Journal of Constructional Steel Research, 2007, Vol. 63, pp. 194-210.

[38] Çevik, A.A., "New Formulation for Longitudinally Stiffened Webs Subjected to Patch Loading”, Journal of Constructional Steel Research, 2007, Vol. 63, pp. 1328-40.

[39] Gholizadeh, S., Pirmoz, A. and Attarnejad, R., "Assessment of Load Carrying Capacity of Castellated Steel Beams by Neural Networks”, Journal of Constructional Steel Research, 2011, Vol. 67, pp. 770-779. 